\title{
NOAA Operational Microwave Sounding Radiometer Data Quality Monitoring and Anomaly Assessment Using COSMIC GNSS Radio-Occultation Soundings
}

\author{
Robbie Iacovazzi ${ }^{1, *}$, Lin Lin $^{2}\left(\mathbb{D}\right.$, Ninghai Sun $^{1}$ and Quanhua Liu ${ }^{3}$ \\ 1 GST Incorporated, 7855 Walker Drive, Suite 200, Greenbelt, MD 20770, USA; Ninghai.Sun@noaa.gov \\ UMD/ESSIC, 5825 University Research Court, Suite \#4001, College Park, MD 20740, USA; Lin.Lin@noaa.gov \\ 3 NOAA/NESDIS/STAR, 5830 University Research Court, College Park, MD 20740, USA; \\ Quanhua.Liu@noaa.gov \\ * Correspondence: Robert.Iacovazzi@noaa.gov; Tel.: +1-301-683-3553
}

Received: 28 January 2020; Accepted: 29 February 2020; Published: 4 March 2020

\begin{abstract}
National Oceanic and Atmospheric Administration (NOAA) operational Advanced Technology Microwave Sounder (ATMS) and Advanced Microwave Sounding Unit-A (AMSU-A) data used in numerical weather prediction and climate analysis are essential to protect life and property and maintain safe and efficient commerce. Routine data quality monitoring and anomaly assessment is important to sustain data effectiveness. One valuable parameter used to monitor microwave sounder data quality is the antenna temperature $(\mathrm{Ta})$ difference $(\mathrm{O}-\mathrm{B})$ computed between direct instrument Ta measurements and forward radiative transfer model (RTM) brightness temperature $(\mathrm{Tb})$ simulations. This requires microwave radiometer data to be collocated with atmospheric temperature and moisture sounding profiles, so that representative boundary conditions are used to produce the RTM-simulated Tb values. In this study, Constellation Observing System for Meteorology, Ionosphere, and Climate/Formosa Satellite Mission 3 (COSMIC) Global Navigation Satellite System (GNSS) Radio Occultation (RO) soundings over the ocean and equatorward of $60^{\circ}$ latitude are used as input to the Community RTM (CRTM) to generate simulated NOAA-18, NOAA-19, Metop-A, and Metop-B AMSU-A and S-NPP and NOAA-20 ATMS Tb values. These simulated Tb values, together with observed Ta values that are nearly simultaneous in space and time, are used to compute Ta O-B statistics on monthly time scales for each instrument. In addition, the CRTM-simulated Tb values based on the COSMIC GNSS RO soundings can be used as a transfer standard to inter-compare Ta values from different microwave radiometer makes and models that have the same bands. For example, monthly Ta O-B statistics for NOAA-18 AMSU-A Channels 4-12 and NOAA-20 ATMS Channels 5-13 can be differenced to estimate the "double-difference" Ta biases between these two instruments for the corresponding frequency bands. This study reveals that the GNSS RO soundings are critical to monitoring and trending individual instrument O-B Ta biases and inter-instrument "double-difference" Ta biases and also to estimate impacts of some sensor anomalies on instrument Ta values.
\end{abstract}

Keywords: remote sensing; joint polar satellite system; advanced technology microwave sounder; COSMIC-1; GNSS radio occultation; satellite instrument performance monitoring and anomaly detection; data quality tracking

\section{Introduction}

The Advanced Technology Microwave Sounder (ATMS) and Advanced Microwave Sounding Unit (AMSU)-A satellite instruments have been critical in improving numerical weather prediction 
(NWP) [1,2] and extending the long-term mid-tropospheric temperature climate time series of the Microwave Sounding Unit (MSU) [3-6], the predecessor instrument of AMSU-A and ATMS. Such projects have revealed that inherent calibration-related antenna temperature (Ta) biases and bias trends within and between operating AMSU-A and/or ATMS instruments must be detected and corrected in order to utilize these satellite data in NWP and climate analyses without the risk of significant errors. Thus, monitoring the quality of National Oceanic and Atmospheric Administration (NOAA) operational microwave radiometer data is critical to ensuring that NOAA meets its mission of protecting life and property, and maintaining safe and efficient commerce.

The history of AMSU-A and ATMS radiometers used operationally by NOAA are listed in Table 1. The table shows that the AMSU-A radiometer has been manifested on NOAA Polar Operational Environmental Satellite (POES) and EUMETSAT Polar System (EPS) Metop satellite platforms. Meanwhile, ATMS has been manifested on the NOAA Joint Polar Satellite System (JPSS) and Suomi National Polar Partnership (S-NPP) satellite platforms. Given the importance of microwave sounding satellite instruments to weather forecasting and climate analysis, it is imperative to monitor their data quality.

Table 1. NOAA operational microwave sounder instrument name, satellite platform, and operational onset date and August 2019 status.

\begin{tabular}{cccc}
\hline Instrument & Satellite Platform & Operational Onset Date & August 2019 Operational Status \\
\hline AMSU-A & POES NOAA-15 & 1998DEC15 & (Operating) Channel 11 and 14 not functional \\
AMSU-A & POES NOAA-16 & 2001MAR20 & (Decommissioned 2014JUN09) \\
AMSU-A & POES NOAA-17 & 2002JUN24 & (Decommissioned 2003OCT) \\
AMSU-A & POES NOAA-18 & 2005AUG30 & (Operating) \\
AMSU-A & POES NOAA-19 & 2009JUN02 & (Operating) \\
AMSU-A & EPS Metop-A & 2007MAY15 & (Operating) \\
AMSU-A & EPS Metop-B & 2013JAN29 & (Operating) \\
AMSU-A & EPS Metop-C & 2019MAR21 & (Operating) \\
ATMS & S-NPP & 2012MAR06 & (Operating) \\
ATMS & JPSS NOAA-20 & 2018MAY30 & \\
\hline
\end{tabular}

Microwave radiometer Ta measurement monitoring, important for diagnosing instrument performance degradation of the sensors listed in Table 1 , has predominately been carried out using the Simultaneous Nadir Overpass (SNO) and the Radiative Transfer Model (RTM) Background Simulation (BS) methods, summarized briefly below.

The SNO method is based on the fact that many polar-orbiting satellites revolve around the Earth at slightly different periods, which causes them to occasionally view the same nadir location at nearly the same time. Ideally, identical radiometers flown on different satellites that simultaneously view the same exact Earth target should produce redundant observations. Any deviation from these results would be attributable to relative calibration differences between the "identical" radiometers. Taking advantage of this concept, the SNO method was developed to estimate and track relative calibration-related measurement biases between visible/infrared radiometers flown on-board different polar-orbiting satellites [7-9]. For a given pair of polar-orbiting satellites, the SNO method analysis is performed for near-nadir observations close to satellite orbital intersections that have a relatively small time difference ( $\sim 30 \mathrm{~s})$. The SNO method was extended to microwave radiometers by Iacovazzi and Cao $[10,11]$.

The RTM-BS method entails simple comparison of radiance, Ta or brightness temperature $(\mathrm{Tb})$ values observed by an instrument with respect to simulated radiance or Tb by an RTM. In order to implement this method in clear-sky regions, atmospheric sounding data that includes pressure, temperature, water vapor mixing ratio, and ozone mixing ratio are needed to establish representative boundary conditions for the RTM. There are diverse atmospheric sounding sources that can be used to support this method. These include soundings generated from traditional radiosondes, NWP model output, and Global Navigation Satellite System (GNSS) Radio-Occultation (RO). Once simulated 
background (B) $\mathrm{Tb}$ values are computed, they can be subtracted from observed (O) Ta values to yield O-B Ta biases. Application of this method to the S-NPP ATMS using National Centers for Environmental Prediction (NCEP) Global Forecast System (GFS) 6-hr forecast outputs can be found in a paper by Weng et al. [12].

In this study, we implement the RTM-BS method by harnessing the Constellation Observing System for Meteorology, Ionosphere, and Climate/Formosa Satellite Mission 3 (COSMIC-1/FORMOSAT3, hereafter referred to as COSMIC for brevity) GNSS-RO sounding data to establish boundary conditions for the Community Radiative Transfer Model (CRTM). Simulated Tb from the CRTM is used to estimate monthly-average O-B Ta bias for each operational AMSU-A and ATMS instrument commissioned after 1 January 2000 except for Metop-C AMSU-A-i.e., NOAA-18, NOAA-19, Metop-A and Metop-B AMSU-A and S-NPP and NOAA-20 ATMS. Furthermore, using the CRTM-simulated Tb values as a transfer standard, the monthly-average O-B Ta bias values for each instrument can be the foundation to inter-compare Ta observations from different microwave radiometer makes and models. Note that the Metop-C AMSU-A is not analyzed in this study because the Ta product was undergoing validation, while the bulk of this study was being performed.

In the next section, we briefly describe the AMSU-A and ATMS instruments and their data, as well as COSMIC GNSS RO observations. Section 3 discusses the method of microwave radiometer and GNSS RO data collocation, as well as providing a brief discussion of the CRTM. Section 4 provides monthly-average O-B Ta bias trends, and double-difference Ta bias trends based on monthly-average O-B Ta bias values from each pair of operational microwave radiometers. Section 4 also provides examples of the power of this method to support operational microwave radiometer anomaly assessment. Finally, in Section 5 a summary is provided.

\section{Instruments and Observations}

Section 2.1 offers overviews of the AMSU/ATMS instruments, and the common sounding channels between them that are selected for this study. Section 2.2 describes the nature of the COSMIC GNSS RO observations, which form the basis of most of the atmospheric sounding inputs needed by the CRTM.

\subsection{AMSU and ATMS Microwave Radiometer Instrument Overviews}

The Advance Microwave Sounding Unit (AMSU) is composed of two units, AMSU-A and AMSU-B. Since the AMSU-A instrument contains atmospheric sounding channels that produce data that can be easily compared with the CRTM-simulated Tb values generated using soundings based on the COSMIC GNSS RO data, the AMSU-A will only be described here. The 15-channel AMSU-A satellite radiometer was designed to replace the 4-channel Microwave Sounding Unit (MSU), which has flown on several POES missions since 1979. In Table 2, the specifications for central frequency, Noise Equivalent Delta Temperature (NEDT) and accuracy, polarization, and nominal beam width and field of view size at nadir of each AMSU-A radiometer channel is listed [13]. The physics behind the choice of these channels can be visualized with the aid of Figure 1, which is actually a combination of figures taken from $[14,15]$. 
Table 2. Specifications for AMSU-A channel central frequency, Noise Equivalent Delta Temperature (NEDT) and accuracy, polarization, and nominal beam width and field of view size at nadir.

\begin{tabular}{|c|c|c|c|c|}
\hline Channel Number & Central Frequency (MHz) & $\begin{array}{l}\text { Specified NEDT/Accuracy } \\
\text { (K) }\end{array}$ & Polarization & $\begin{array}{c}\text { 3dB Beam width and } \\
\text { FOV Nadir Size } \\
\text { (deg \& km) }\end{array}$ \\
\hline 1 & 23,800 & $0.30 / 1.0$ & $\mathrm{~V}$ & $3.3 \& 50$ \\
\hline 2 & 31,400 & $0.30 / 1.0$ & $\mathrm{~V}$ & $3.3 \& 50$ \\
\hline 3 & 50,300 & $0.40 / 1.0$ & $\mathrm{~V}$ & $3.3 \& 50$ \\
\hline 4 & 52,800 & $0.25 / 1.0$ & $\mathrm{~V}$ & $3.3 \& 50$ \\
\hline 5 & $53,596 \pm 115$ & $0.25 / 1.0$ & $\mathrm{H}$ & $3.3 \& 50$ \\
\hline 6 & 54,400 & $0.25 / 1.0$ & $\mathrm{H}$ & $3.3 \& 50$ \\
\hline 7 & 54,940 & $0.25 / 1.0$ & $\mathrm{~V}$ & $3.3 \& 50$ \\
\hline 8 & 55,500 & $0.25 / 1.0$ & $\mathrm{H}$ & $3.3 \& 50$ \\
\hline 9 & $\mathrm{f} 0=57,290.344$ & $0.25 / 1.0$ & $\mathrm{H}$ & $3.3 \& 50$ \\
\hline 10 & $\mathrm{f} 0 \pm 217$ & $0.40 / 1.0$ & $\mathrm{H}$ & $3.3 \& 50$ \\
\hline 11 & $\mathrm{f} 0 \pm 322.2 \pm 48$ & $0.40 / 1.0$ & $\mathrm{H}$ & $3.3 \& 50$ \\
\hline 12 & $\mathrm{f} 0 \pm 322.2 \pm 22$ & $0.60 / 1.0$ & $\mathrm{H}$ & $3.3 \& 50$ \\
\hline 13 & $\mathrm{f} 0 \pm 322.2 \pm 10$ & $0.80 / 1.0$ & $\mathrm{H}$ & $3.3 \& 50$ \\
\hline 14 & $\mathrm{f} 0 \pm 322.2 \pm 4.5$ & $1.20 / 1.0$ & $\mathrm{H}$ & $3.3 \& 50$ \\
\hline 15 & 89,000 & $0.50 / 1.0$ & $\mathrm{~V}$ & $3.3 \& 50$ \\
\hline
\end{tabular}

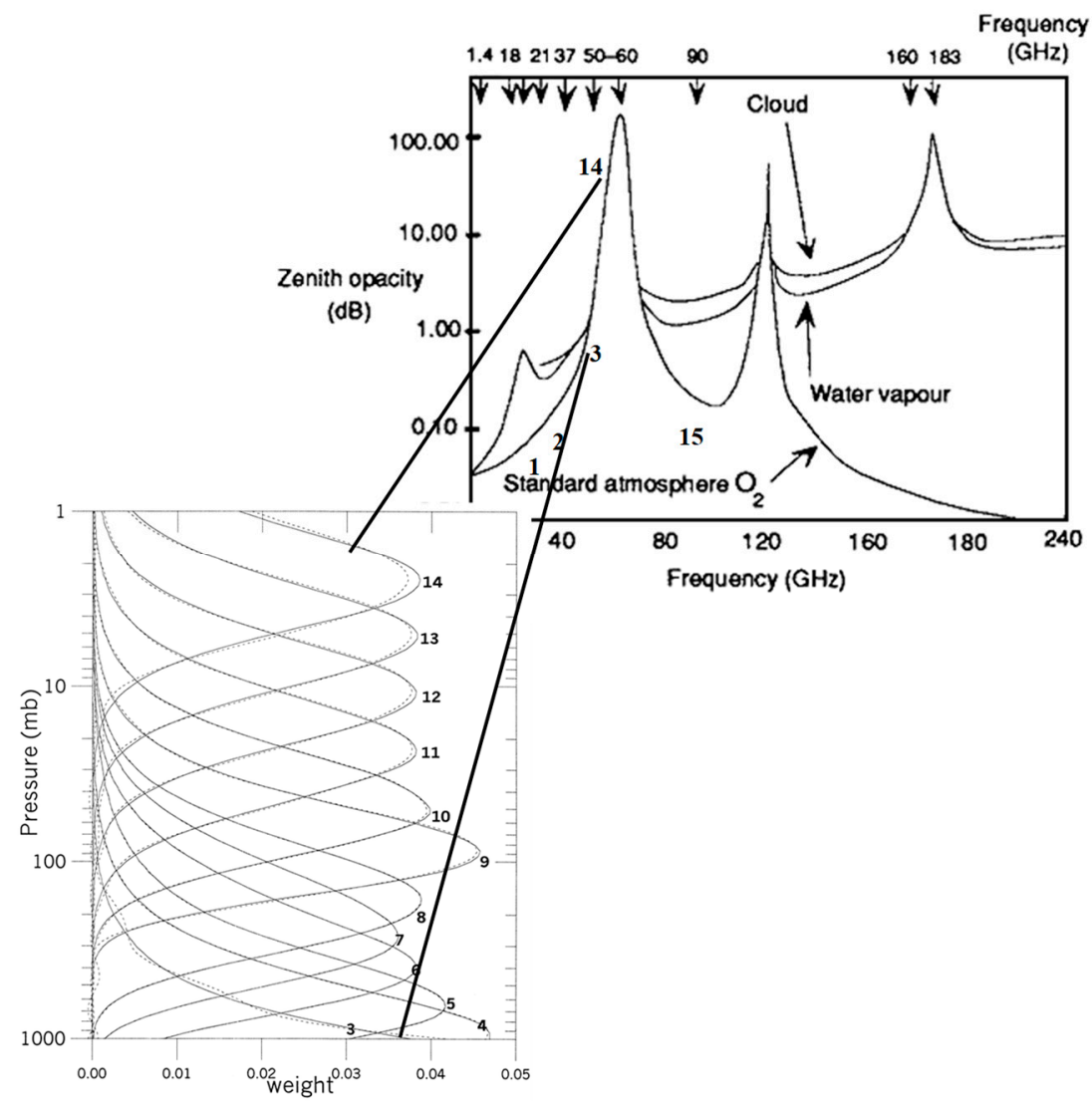

Figure 1. Atmospheric zenith opacity as a function of microwave frequency (top- [15]), where AMSU-A Channels (Chs) 1-3 and 14-15 are provided for reference. Additionally given are the weighting functions for AMSU-A sounding Chs 3-14 (bottom-[14] (C) Copyright 2000 AMS) in the oxygen absorption band.

In this figure, Channels (Chs) 1, 2, and 15 are considered surface channels in the absence of clouds and water vapor because of their relatively low atmospheric zenith opacity. The Ch 1 and 2 Ta values are directly proportional to surface emissivity, which has values of approximately 1.0 and 0.5 over land and ocean, respectively. Over ocean, relatively cool Ch 1 and 2 Ta values at a given location increase with cloud liquid water and precipitation amount, which leads to estimates of these physical quantities over ocean. Sea ice is also detected in these channels using similar reasoning. All of these properties of Chs 1 and 2 can be found in Ch 15, except that the atmosphere becomes increasingly opaque in this 
channel with increasing water vapor. Furthermore, Ch 15 is sensitive to ice particle scattering, which lends it to be used to estimate convective precipitation. The AMSU-A Chs 3 to 14 are sounding channels that utilize the strongly increasing opacity of the atmosphere as frequency approaches the center of the $60 \mathrm{GHz}$ oxygen absorption band. Note that sounding Chs 3 and 4 are strongly influenced by the surface, so Chs 4 to 12 are the channels used in conjunction with the COSMIC GNSS RO soundings.

The nominal beam width and NEDT specified in Table 2 are a source of variability in the Ta bias statistics. Nominal beam width determines the size of the region where $50 \%$ of the microwave energy is coming from in a given scene. A nominal beam width of 3.3 degrees leads to a nadir footprint of nearly $50 \mathrm{~km}$. The AMSU-A instrument scans $\pm 48.33^{\circ}$ from nadir to complete a total of 30 field of view (FOV) measurements along scan lines, which leads to a swath width of $2243 \mathrm{~km}$.

On-board calibration of total power microwave sounding radiometers, such as AMSU-A and ATMS, is achieved by observing cold space and a well-characterized internal blackbody target during each revolution of the scan reflector antenna. Each AMSU-A eight-second full scan revolution begins by the scan antenna sampling earth scenes. After observing the earth, the reflector rotates such that cold space is measured when the antenna moves to a position that points to an unobstructed view of space-i.e., between the Earth's limb and the spacecraft horizon. After the cold space observations, the internal blackbody is viewed when the antenna rotates to the instrument anti-nadir direction, where the blackbody is located. After these observations, the scan reflector rotates back to an earth view, and then continues the next scan cycle. The calibration measurements are used to accurately determine the so-called radiometer transfer function that relates the measured digitized output (i.e., counts) to a radiance, which then can be expressed as radiometric Ta through the Planck function. More about the calibration of AMSU-A can be found in the NOAA KLM User's Guide [16].

The ATMS is a cross-track scanning microwave radiometer that is manifested on the S-NPP and JPSS satellites. In Table 3, the specifications of spectral value, NEDT and accuracy, polarization and nominal beam width in the cross- and along-track directions and the field of view size at nadir of each ATMS radiometer channel is listed [17].

Table 3. Specifications for ATMS channel central frequency, NEDT and accuracy, polarization, and nominal beam width and field of view size at nadir.

\begin{tabular}{|c|c|c|c|c|}
\hline Channel Number & Central Frequency (MHz) & $\begin{array}{l}\text { Specified NEDT/Accuracy } \\
\text { (K) }\end{array}$ & Polarization & $\begin{array}{l}\text { 3dB Beam width and } \\
\text { FOV Nadir Size } \\
\text { (deg \& km) }\end{array}$ \\
\hline 1 & 23,800 & $0.70 / 1.0$ & $\mathrm{~V}$ & $5.2 \& 75$ \\
\hline 2 & 31,400 & $0.80 / 1.0$ & $\mathrm{~V}$ & $5.2 \& 75$ \\
\hline 3 & 50,300 & $0.9 / 0.75$ & $\mathrm{H}$ & $2.2 \& 32$ \\
\hline 4 & 51,760 & $0.7 / 0.75$ & $\mathrm{H}$ & $2.2 \& 32$ \\
\hline 5 & 52,800 & $0.7 / 0.75$ & $\mathrm{H}$ & $2.2 \& 32$ \\
\hline 6 & $53,596 \pm 115$ & $0.7 / 0.75$ & $\mathrm{H}$ & $2.2 \& 32$ \\
\hline 7 & 54,400 & $0.7 / 0.75$ & $\mathrm{H}$ & $2.2 \& 32$ \\
\hline 8 & 54,940 & $0.7 / 0.75$ & $\mathrm{H}$ & $2.2 \& 32$ \\
\hline 9 & 55,500 & $0.7 / 0.75$ & $\mathrm{H}$ & $2.2 \& 32$ \\
\hline 10 & $\mathrm{f} 0=57,290.344$ & $0.75 / 0.75$ & $\mathrm{H}$ & $2.2 \& 32$ \\
\hline 11 & $\mathrm{f} 0 \pm 217$ & $1.2 / 0.75$ & $\mathrm{H}$ & $2.2 \& 32$ \\
\hline 12 & $\mathrm{f} 0 \pm 322.2 \pm 48$ & $1.2 / 0.75$ & $\mathrm{H}$ & $2.2 \& 32$ \\
\hline 13 & $\mathrm{f} 0 \pm 322.2 \pm 22$ & $1.5 / 0.75$ & $\mathrm{H}$ & $2.2 \& 32$ \\
\hline 14 & $\mathrm{f} 0 \pm 322.2 \pm 10$ & $2.4 / 0.75$ & $\mathrm{H}$ & $2.2 \& 32$ \\
\hline 15 & $\mathrm{f} 0 \pm 322.2 \pm 4.5$ & $3.6 / 0.75$ & $\mathrm{H}$ & $2.2 \& 32$ \\
\hline 16 & 88,200 & $0.5 / 1.0$ & $\mathrm{~V}$ & $2.2 \& 32$ \\
\hline 17 & 165,500 & $0.6 / 1.0$ & $\mathrm{H}$ & $1.1 \& 16$ \\
\hline 18 & $183,310 \pm 7000$ & $0.8 / 1.0$ & $\mathrm{H}$ & $1.1 \& 16$ \\
\hline 19 & $183,310 \pm 4500$ & $0.8 / 1.0$ & $\mathrm{H}$ & $1.1 \& 16$ \\
\hline 20 & $183,310 \pm 3000$ & $0.8 / 1.0$ & $\mathrm{H}$ & $1.1 \& 16$ \\
\hline 21 & $183,310 \pm 1800$ & $0.8 / 1.0$ & $\mathrm{H}$ & $1.1 \& 16$ \\
\hline 22 & $183,310 \pm 1000$ & $0.9 / 1.0$ & $\mathrm{H}$ & $1.1 \& 16$ \\
\hline
\end{tabular}

The ATMS instrument scans $\pm 52.725^{\circ}$ from nadir to complete a total of 96 field of view (FOV) measurements along scan lines. ATMS has a swath width of $2700 \mathrm{~km}$, which leaves almost no data 
gap even near the equator. The instrument is configured with a total of 22 channels at microwave frequencies ranging from 23 to $183 \mathrm{GHz}$. Calibration of ATMS is similar to that described in the previous subsection for AMSU-A, except some important radiometric corrections have been made to the data to improve accuracy. More information about ATMS calibration can be found in articles by Weng et al. [12], Han et al. [18], and Weng et al. [17].

When comparing the ATMS and AMSU-A instrument channels, ATMS includes a channel at $51.76 \mathrm{GHz}$ that is not present in AMSU-A. Additionally, the $89.0 \mathrm{GHz}$ channel of AMSU-A is not equivalent to the $88.2 \mathrm{GHz}$ channel of ATMS. On the other hand, ATMS shares the same central frequencies with 14 AMSU-A channels. Not all of these shared channels are included in the present analysis though. The reason for this is that the COSMIC GNSS RO soundings report atmospheric pressure, temperature and water vapor between the surface and $40 \mathrm{~km}$ at $100 \mathrm{~m}$ intervals. For this study, measurements of surface parameters, and sounding parameters above $3 \mathrm{mb}$, are assumed to be climatological values. Therefore, the CRTM simulations performed using the synthesis of COSMIC GNSS RO sounding measurements, and climatological surface and upper atmosphere sounding estimates, leads to the highest skill in comparing CRTM simulated and AMSU-A and ATMS observed Ta values for common AMSU-A and ATMS channels that have weighting functions contained almost entirely between the surface and $40 \mathrm{~km}$. This represents AMSU-A Chs 4-12 and ATMS Chs 5-13.

Another important architectural change between ATMS and AMSU-A is that the polarization of AMSU-A Ch 4 and 7 (V-pol) and ATMS Ch 5 and 8 (H-pol) are different. Since AMSU-A Ch 4 and ATMS $\mathrm{Ch} 5$ receive a large portion of energy from the surface, this will lead to quite different absolute values for them over ocean. On the other hand, the double difference with respect to CRTM-simulated values should eliminate this large absolute temperature bias. For AMSU-A Ch 7 and ATMS Ch 8, there should not be such an absolute difference, since radiation originating from the atmosphere in the microwave is considered unpolarized, and the amount of energy from the surface for this sounding channel is much smaller.

\subsection{COSMIC GNSS RO Observations Overview}

The GNSS RO sounding method is a limb-sounding technique that makes use of radio signals emitted from GNSS satellites for determining the temperature and water vapor profiles of the Earth's atmosphere. Assuming spherical symmetry of the atmospheric refractive index, vertical profiles of bending angle and refractivity can be derived from the raw $\mathrm{RO}$ measurements of the excess Doppler shift of the radio signals transmitted by GNSS satellites [19]. Since temperature and water vapor variations in the atmosphere can elicit small variations of this altitude-dependent refractivity, profiles of refractivity and their subtle variability can then be used to generate profiles of the temperature and water vapor retrieval using a one-dimensional variational data assimilation (1D-Var) algorithm [20,21]. The COSMIC Data Analysis and Archive Center (CDAAC) wet (wetPrf) retrieval is used for this software tool. A brief description of a 1D-Var algorithm for GNSS RO retrieval is provided at https://cdaac-www.cosmic.ucar.edu/cdaac/doc/overview.html.

The COSMIC satellite system consists of a constellation of six low-Earth-orbit (LEO) micro-satellites, and was launched on April 15, 2006. Each LEO follows a circular orbit $512 \mathrm{~km}$ above the Earth surface, with an inclination angle of $72^{\circ}$. Currently, since only one COSMIC instrument is functioning, there are only up to about 250 soundings daily, and this number can be much lower for some days. The vertical resolution is $0.1 \mathrm{~km}$ from surface to $39.9 \mathrm{~km}$, and each GNSS-RO measurement quantifies an integrated atmospheric refraction effect over a few hundred kilometers along a ray path centered at the tangent point. The global mean differences between COSMIC and high-quality reanalysis within the height range between 8 and $30 \mathrm{~km}$ are estimated to be about $0.65 \mathrm{~K}$ [22], while a more recent study of soundings over the Arctic estimated a structural uncertainty (due to different data processing approaches) of about $0.72 \mathrm{~K}$ [23]. The precision of COSMIC GNSS RO soundings, estimated by comparison of closely collocated Challenging Minisatellite Payload (CHAMP) and Scientific Application Satellite-C (SAC-C) GNSS-RO soundings, is approximately $0.05 \mathrm{~K}$ in the upper troposphere and lower stratosphere [24]. 
In the water vapor abundant region in the lower troposphere (e.g., when temperature is greater than $270 \mathrm{~K}$ ), the precision reduces to about $0.1 \mathrm{~K}$. In the ionosphere regions, GNSS profiles become less accurate due to residual ionospheric effect. The estimated precision of COSMIC GNSS RO soundings is approximately $0.2 \mathrm{~K}$ in the ionosphere.

\section{Method}

In this section, a summary of the method to monitor and trend AMSU-A and ATMS Temperature Data Record (TDR) with RTM-BS output is described. The first subsection describes the methods to screen the AMSU-A and ATMS data, and the COSMIC GNSS RO soundings, and to collocate these data. The second subsection offers a brief description of the CRTM, and the final subsection presents a list of the statistical analysis of the observed minus background (O-B) Ta values computed from AMSU-A and ATMS observations and associated CRTM simulations.

\subsection{Microwave Radiometer and COSMIC GNSS RO Observation Screening and Collocation Method Subsection}

In this inter-comparison study, the data associated with the COSMIC GNSS RO soundings and the microwave radiometer measurements must be screened and then efficiently collocated. Screening criteria applied to both data sets include limiting them to ocean regions equatorward of $60^{\circ}$ latitude. Since the physical properties of Ta for the sounding channels are affected by clouds, a cloud detection algorithm similar to [25] is applied to separate the data in clear sky conditions over ocean from the total microwave radiometer measurements [12]. As the GNSS radio signal passes through the atmosphere, its ray path is bent over due to variations of atmospheric refraction. Therefore, the geolocation of the perigee point (also called tangent point) of a single GNSS RO profile varies with altitude. Therefore, soundings are rejected where the location variation of sounding measurement geolocation versus altitude is more than $150 \mathrm{~km}$, because the GNSS RO resolution is about $300 \mathrm{~km}$. This eliminates $5 \%$ or less of soundings that may have relatively large vertical variations of geolocation with altitude. When the sounding geolocation variability with altitude is constrained, it allows spatial constraints to be placed on the collocation process that makes it much more efficient.

The collocation criteria are set by a time difference of no more than three hours and a horizontal spatial separation of less than $50 \mathrm{~km}$. If there are multiple microwave radiometer pixel measurements satisfying these collocation criteria, the one that is closest to the related COSMIC sounding is chosen and others are discarded. As an efficiency, the initial spatial bounding circle to screen collocations is established to ensure that if no matchup is found at the first viable sounding level, then it is impossible that there with be a matchup at any higher sounding level. For a given GNSS RO sounding, this spatial bounding circle is defined by a sum of (1) the maximum distance between the lowest sounding level location and all the other sounding level locations above, (2) the $50 \mathrm{~km}$ distance threshold, and (3) a $25 \mathrm{~km}$ distance padding to be conservative on the side of finding matchups. If no matchups in an ATMS granule or AMSU-A file are found at the lowest level with this screen, then the program goes to the next granule or file without trying to find matchups for the higher sounding levels.

As mentioned above, the geolocation of the tangent point of a single GNSS RO profile varies with altitude. On the other hand, a satellite measurement at a specific frequency represents a weighted average of radiation emitted from different layers of the atmosphere. The magnitude of such a weighting is determined by a channel-dependent weighting function (WF). The measured radiation is most sensitive to the atmospheric temperature at the altitude where the WF reaches a maximum. The WF also varies with scan angle [26]. For each channel, the altitude of the peak WF is the lowest at nadir and increases with the scan angle. Considering the geolocation change of the perigee point of a GNSS RO profile with altitude, the geolocation of a given GNSS RO sounding at the altitude where the WF for each collocated microwave radiometer field of view (FOV) of a particular sounding channel reaches the maximum is used for implementing the spatial collocation criteria of less than $50 \mathrm{~km}$. The altitude of the maximum WF is determined by inputting the U.S. standard atmosphere into the CRTM. 


\subsection{Summary of the Community Radiative Transfer Model}

The CRTM is developed and distributed by the US Joint Center for Satellite Data Assimilation (JCSDA). The model is publicly available and may be downloaded from ftp://ftp.emc.ncep.noaa.gov/ jcsda/CRTM/REL-2.1.3/. The CRTM is a sensor-channel-based radiative transfer model [27-30] and is widely used for microwave and infrared satellite data assimilation and remote sensing applications. It includes modules that compute the satellite-measured thermal radiation from gaseous absorption, absorption and scattering of radiation by aerosols and clouds, and emission and reflection of radiation by the Earth surface. The input to the CRTM includes atmospheric state variables-e.g., temperature, water vapor, pressure, and ozone concentration at user defined layers, and optionally, liquid water content and mean particle size profiles for up to six cloud types and surface state variables and parameters including the emissivity, skin temperature, and wind. In addition to CRTM (i.e., the forward model), the corresponding tangent-linear, adjoint, and K-matrix models have also been included in the CRTM package.

As outlined in Section 2.1, in this study the vertical profiles of temperature, water vapor and pressure are obtained as a hybrid of COSMIC GNSS RO sounding retrievals and climatological values of surface parameters and sounding parameters above $3 \mathrm{mb}(\sim 40 \mathrm{~km})$. The mixing ratio profile of ozone is set to be equal to the U.S. standard atmospheric state. For simplicity, no cloud or aerosols are considered in the radiative transfer simulation. The emissivity is derived from the CRTM oceanic surface model at microwave frequencies.

\subsection{AMSU-A and ATMS O-B Antenna Temperature Statistics}

The mission-life time series and statistical results presented in the subsequent section are based on NOAA operational AMSU-A and ATMS observed minus CRTM-simulated background (O-B) monthly-mean Ta bias values. For a given on-orbit AMSU-A or ATMS unit, these values are computed from the set of O-B Ta biases determined from all individual collocated radiometer and COSMIC GNSS $\mathrm{RO}$ data accumulated over each month. The mission-life standard deviation of these monthly-mean O-B Ta bias data provides an estimate of their uncertainty and can be used to approximate the mission-life population standard deviation.

For temporal periods of overlap between sensors, the monthly-mean Ta biases between sensors can be determined by assigning the CRTM-simulated values as a calibration transfer standard. In this case, simply subtracting the monthly-mean O-B Ta bias values for different instruments establishes these sensor-to-sensor "double-difference" Ta bias statistics. For the purpose of this study, only operational satellites launched after January 1, 2000 will be considered, which includes NOAA-18, NOAA-19, Metop-A and Metop-B AMSU-A and S-NPP and NOAA-20 (JPSS-1) ATMS. Furthermore, the data records here are only processed after October 2012 for AMSU-A data, January 2015 for S-NPP ATMS and December 2017 for JPSS-1 ATMS.

It is important here to stress that the output of CRTM microwave sounding radiometer simulations is radiance or Tb. Meanwhile, this analysis uses AMSU-A and ATMS Ta measurements, because AMSU-A and ATMS both have Ta products, while only ATMS has an official operational Tb product. Although CRTM Ta estimates are available for direct comparison with AMSU-A Ta measurements, we choose to generate CRTM AMSU-A and ATMS Tb simulated values. This makes inter-satellite comparisons between AMSU-A and ATMS more "apples-to-apples." Using the CRTM generated Tb for both AMSU-A and ATMS allows the CRTM to be used as a transfer standard to compute O-B Ta double difference. The key to trending O-B Ta for each instrument is being able to visualize changes, which is in no way compromised by using CRTM simulated $\mathrm{Tb}$.

\section{Results and Discussion}

In the next three subsections, the AMSU-A and ATMS O-B Ta bias analysis results for all collocated radiometer and COSMIC GNSS RO data that pass the imposed spatial and cloud screening criteria 
are presented. Section 4.1 focuses on fine-resolution analysis represented by one-day and one-month global O-B Ta bias maps, to provide an example of the data distribution and population at these time scales. Coarser resolution analyses are depicted in the last two subsections. In Section 4.2, global monthly-mean O-B Ta bias time series plots are given, as well as mission-life mean and standard deviation plots computed from these time series. Finally, in Section 4.3 statistical analysis related to the differences between monthly-mean O-B Ta bias results from instrument pairs-i.e., the sensor-to-sensor "double-difference" Ta bias values-are presented in a similar manner as Section 4.2. Sections 4.2 and 4.3 also highlight microwave sounder anomaly detection and investigation examples to reveal how these monitoring parameters are used in "day-in-the-life" instrument calibration maintenance and sustainment.

\subsection{One-Day and-Month O-B Ta Bias Maps}

According to information about the COSMIC-1/FORMOSAT3 Program captured by the Earth Observation (EO) Portal (https://directory.eoportal.org/web/eoportal/satellite-missions), five of the six COSMIC constellation spacecraft were operating in October 2012, which is the beginning of the time range of this analysis. This configuration led to about 1500 to 2000 GNSS RO soundings per day, uniformly distributed around the globe. By mid-2019, near the end of this analysis, number of COSMIC GNSS RO soundings per day had dropped to about 400-500 due to either satellite instrument decommission or operational instabilities. In this study, we use the COSMIC-1/FORMOSAT3 acquired between October 2012 and August 2019 to perform our analysis.

The data analysis screening process presented in Section 3.1 limits the GNSS RO soundings to clear-sky ocean regions equatorward of $60^{\circ}$ latitude, and the collocation process with the operational satellite microwave radiometer data limits the sample even more. By the end of these processes, the number of collocated radiometer and COSMIC GNSS RO data points on a given day in 2012 could be in the hundreds, while near the end of this analysis in August 2019 that number drops into the tens. The mission-life average of the number of collocated radiometer and COSMIC GNSS RO data matchups accumulated over the course of a month for each channel is given in Table 4 .

Table 4. The mission-life average number of collocated radiometer and COSMIC GNSS RO data matchups accumulated over the course of a month for NOAA-18, NOAA-19, Metop-A, and Metop-B AMSU-A Channels 4-12, and for Suomi-NPP and JPSS-1 ATMS Channels 5-13.

\begin{tabular}{cccccccc}
\hline & \multicolumn{3}{c}{ AMSU-A } & & \multicolumn{3}{c}{ ATMS } \\
\hline Ch \# & NOAA-18 & NOAA-19 & Metop-A & Metop-B & Ch \# & S-NPP & NOAA-20 \\
\hline 4 & 1990 & 2205 & 1881 & 1864 & 5 & 1089 & 415 \\
5 & 1541 & 1860 & 1627 & 1633 & 6 & 1571 & 718 \\
6 & 2380 & 2619 & 2219 & 2207 & 7 & 1594 & 725 \\
7 & 2403 & 2651 & 0 & 2229 & 8 & 1602 & 728 \\
8 & 2408 & 2660 & 3570 & 2233 & 9 & 1609 & 728 \\
9 & 6589 & 6554 & 5794 & 5687 & 10 & 4355 & 1852 \\
10 & 6590 & 6557 & 5794 & 5688 & 11 & 4365 & 1868 \\
11 & 6591 & 6558 & 5795 & 5686 & 12 & 4369 & 1862 \\
12 & 6596 & 6562 & 5800 & 5688 & 13 & 4381 & 1868 \\
\hline
\end{tabular}

Examples of daily global O-B Ta bias maps for NOAA-18 AMSU-A Ch 4 and Ch 12 are provided in Figure 2A,B, respectively. In these figures, each point represents the location of a COSMIC GNSS RO sounding and collocated NOAA-18 AMSU-A observation that was acquired on 31 October 2012. These figures show clearly that upper-air sounding channels such as AMSU-A Ch 12 have a great deal more points than surface-influenced channels like AMSU-A Ch 4. This is due to the fact that data associated with GNSS RO sounding levels closest to the surface are more likely to be missing or have the bad data quality flag set. The color shade of each point represents an O-B Ta bias range, to crudely quantify its value. As expected, the data distribution is fairly uniform over the global oceans 
equatorward of $60^{\circ}$ latitude. Daily O-B Ta bias values at GNSS RO sounding locations are accumulated over a month to create datasets for monthly O-B Ta bias statistics. The monthly O-B Ta bias maps for NOAA-18 AMSU-A Ch 4 and Ch 12 are provided in Figure 3A,B so the reader can gain an appreciation of the large number of observations that are the foundation of monthly statistics.

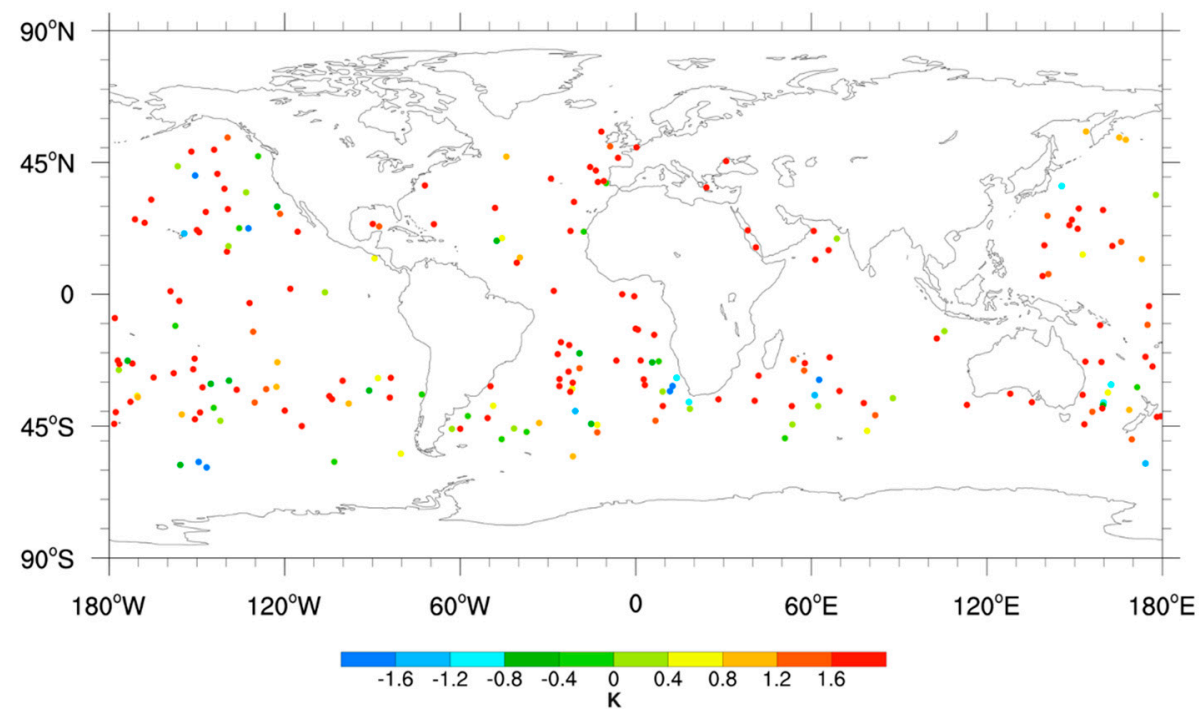

(A)

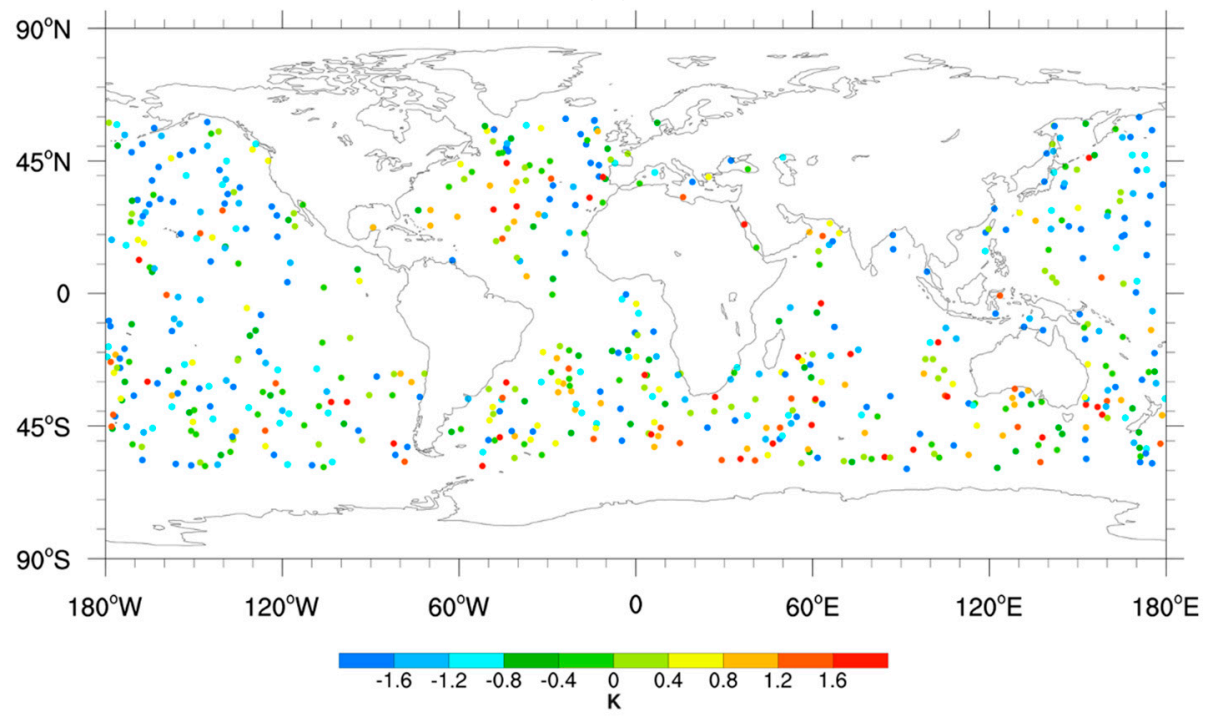

(B)

Figure 2. Daily global O-B Ta bias maps for NOAA-18 AMSU Ch 4 (A) and Ch 12 (B) for 31 October 2012. 




(A)

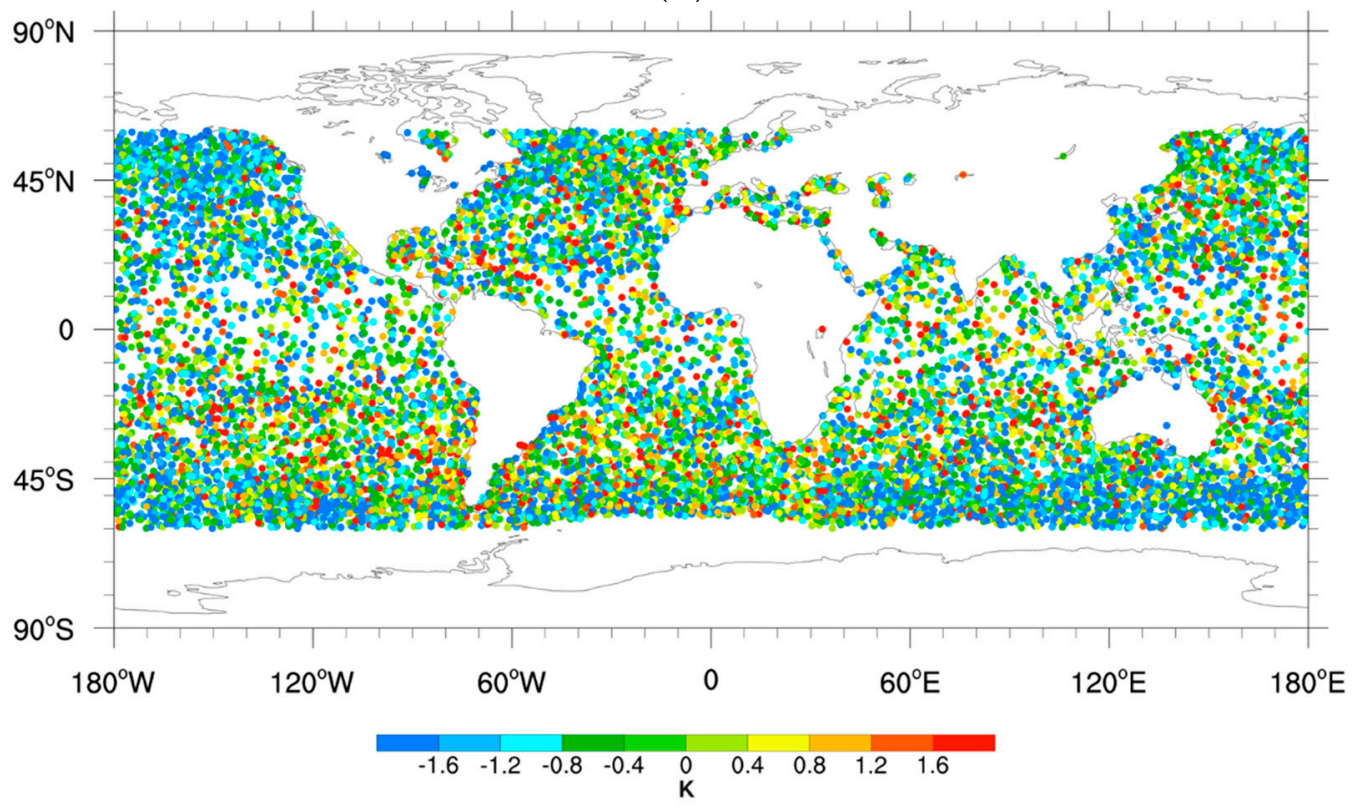

(B)

Figure 3. Monthly global O-B Ta bias maps for NOAA-18 AMSU Ch 4 (A) and Ch 12 (B) for October 2012.

As mentioned above, the number of functioning COSMIC instruments changed dramatically by the end of the record, which resulted in much smaller sample sizes. On the other hand, these reduced sample sizes remain globally well distributed and are adequate to be statistically robust. This is shown in Figure 4A,B with the monthly global O-B Ta bias maps for NOAA-18 AMSU-A Ch 4 and Ch 12 for August 2019. 


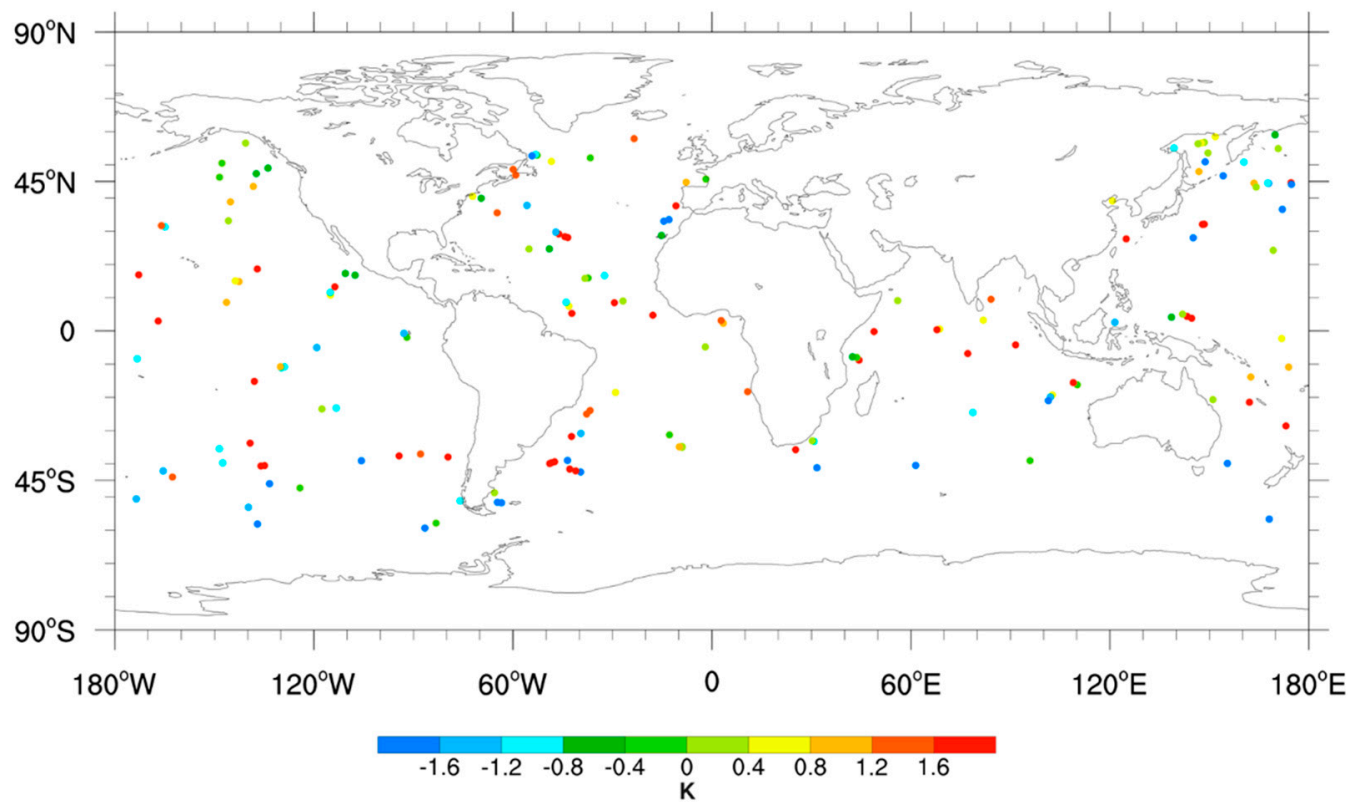

(A)

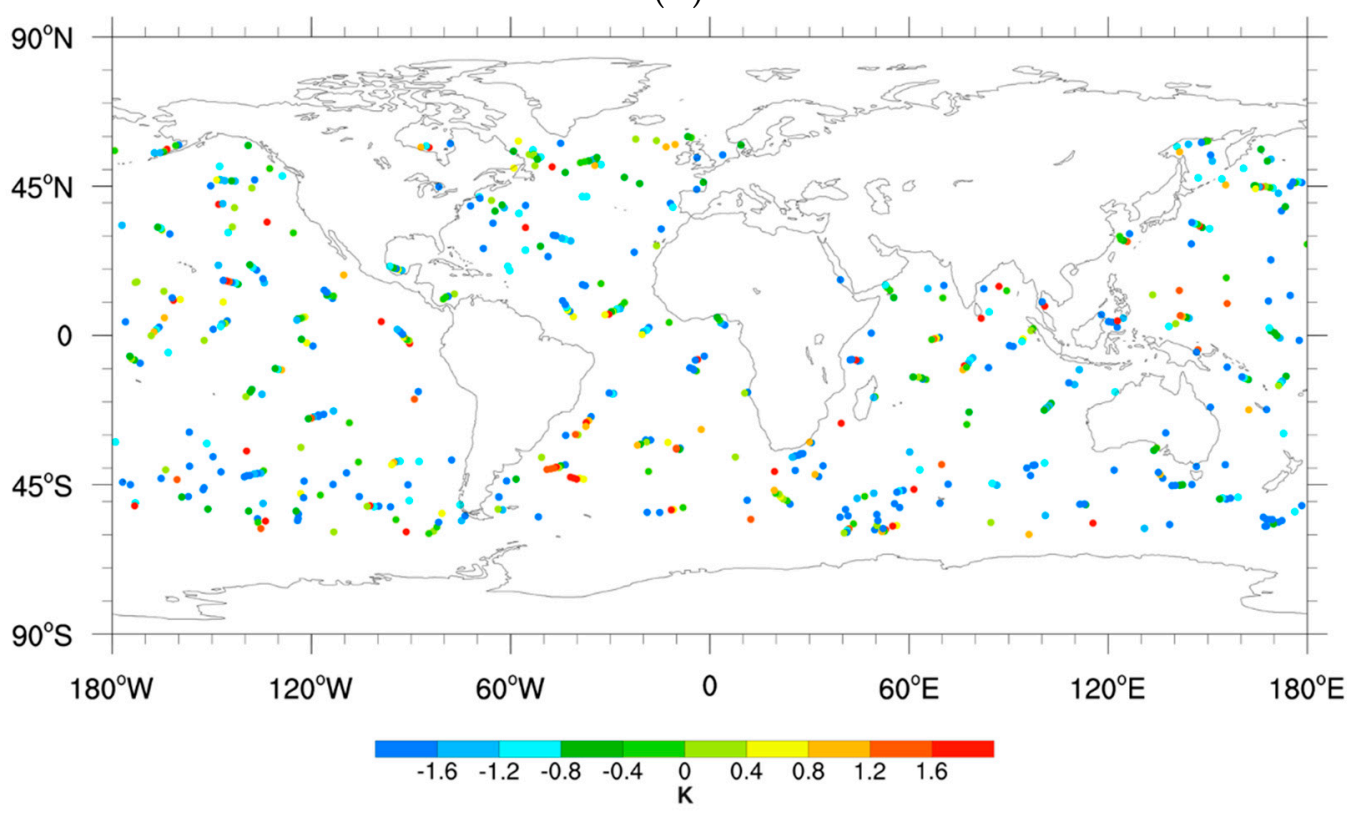

(B)

Figure 4. Monthly global O-B Ta bias maps for NOAA-18 AMSU Ch 4 (A) and Ch 12 (B) for August 2019.

\subsection{Monthly and Mission-Life O-B Ta Bias Statistical Results}

A goal of this paper is to help NOAA operational microwave radiometer data users gain insight into the stability of radiometer observations over instrument mission-life time periods. For this purpose, in this section monthly and mission-life O-B Ta bias statistical results are given for NOAA-18, NOAA-19, Metop-A, and Metop-B AMSU-A, and S-NPP and JPSS-1 ATMS. These statistics include the monthly-mean O-B Ta bias values, as well as mission-life averages of these monthly-mean values, which is called the "mission-life mean" in this study. Mission-life statistics also include the standard deviation of the monthly-mean values. This "mission-life standard deviation" is used to assign an uncertainty to the method.

In Figure 5A, the mission-life mean O-B Ta bias values are plotted as a function of radiometer sounding channel. For ATMS Ch 5 (AMSU-A Ch 4 ) these O-B Ta bias values are about $1 \mathrm{~K}$, while they 
vary between about $-1.5 \mathrm{~K}$ to $0 \mathrm{~K}$ for ATMS Ch 6-13 (AMSU-A Ch 5-12). These salient results are reminiscent of temperature biases found in the COSMIC wetPrf data relative to radiosondes by Wang et al. [31]. In their study, comparisons of COSMIC wetPrf and radiosonde temperatures revealed a positive wetPrf bias that increased from $0.0 \mathrm{~K}$ to $0.5 \mathrm{~K}$ as the atmospheric layer pressure increased from $700 \mathrm{hPa}$ to $925 \mathrm{hPa}$. For layers with pressure less than $700 \mathrm{hPa}$, theses biases between COSMIC wetPrf and radiosonde temperatures were about $-0.2 \mathrm{~K}$ to $-0.3 \mathrm{~K}$. Figure $5 \mathrm{~A}$ also shows a prominent NOAA-19 Ch 8 O-B Ta bias outlier of about $0.5 \mathrm{~K}$. This bias outlier differs substantially from the Ta bias value of about $-1.25 \mathrm{~K}$ for the other instrument makes and models for this $55.5 \mathrm{GHz}$ frequency channel. This figure further reveals that except for the one outlier, the mission-life mean O-B Ta bias values cluster within about $0.5 \mathrm{~K}$ of each other for channels with identical frequencies.

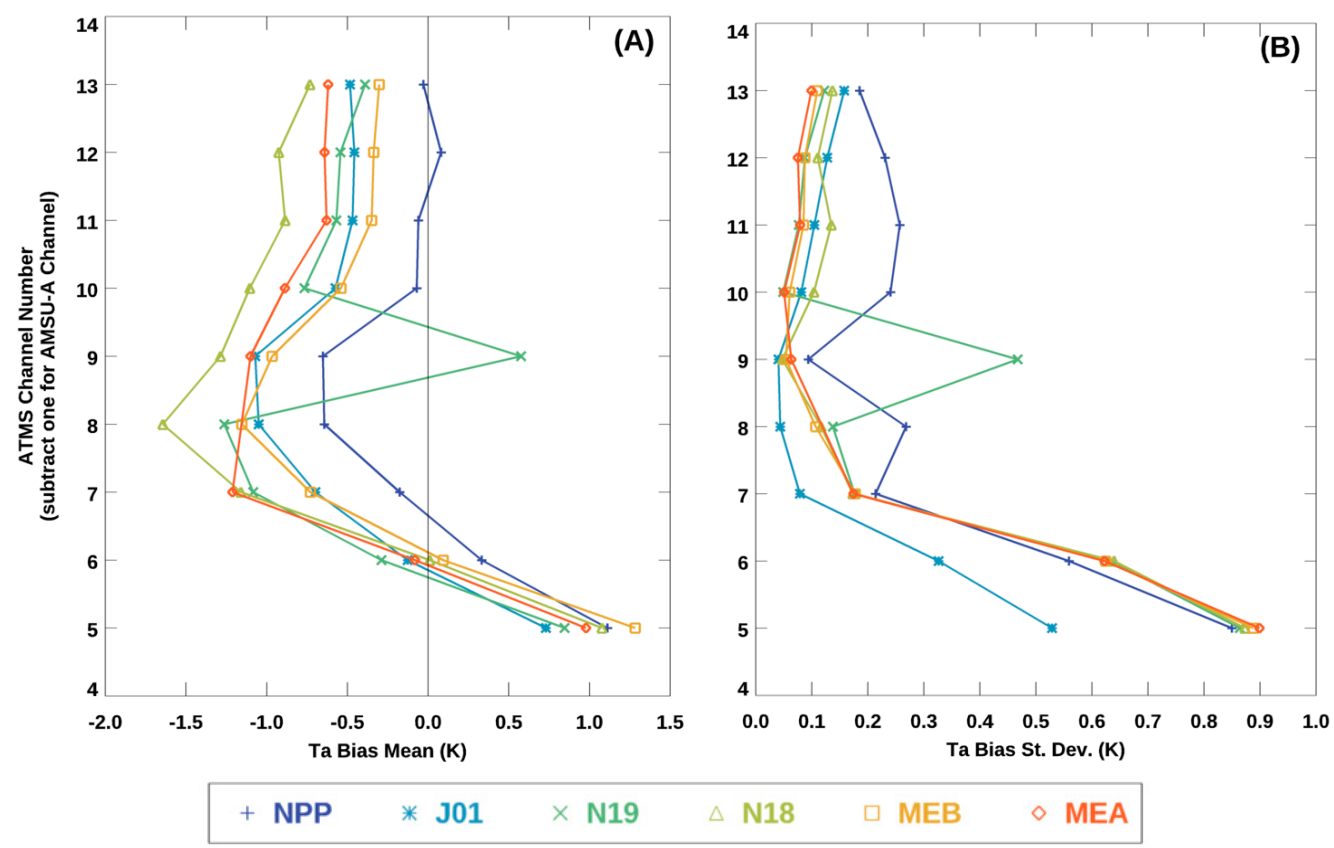

Figure 5. Mission-life mean (A) and standard deviation (B) O-B Ta bias values for NOAA-18 (N18), NOAA-19 (N19), Metop-A (MEA), and Metop-B (MEB) AMSU-A, and S-NPP (NPP) and JPSS-1 (J01) ATMS are plotted for each ATMS channel. The legend below the figures denotes the satellite identifier associated with each line plot. Note in this figure that the corresponding AMSU-A channel is the ATMS channel number minus one.

Figure 5B displays the mission-life standard deviation O-B Ta bias values, which represent a measure of the method uncertainty. This figure shows that these values are typically less than $0.2 \mathrm{~K}$, except for NOAA-19 AMSU-A Ch 8 and ATMS Ch 5-6 (AMSU-A Ch 4-5). The ATMS Ch 5-6 (AMSU-A Ch 4-5) have values greater than $0.6 \mathrm{~K}$ for all instruments other than JPSS-1 ATMS, which has standard deviation values greater than $0.3 \mathrm{~K}$. The Wang et al. study [31] mentioned above revealed that the standard deviation of COSMIC wetPrf and radiosonde temperature biases in the layers from $700 \mathrm{hPa}$ to $150 \mathrm{hPa}$ were $30 \%$ smaller than those between $700 \mathrm{hPa}$ and $925 \mathrm{hPa}$. The even greater relative standard deviation found in Figure 5B for ATMS Ch 5-6 and AMSU Ch 4-5 may be explained by the surface contamination that plagues these radiometer channels. This is not an issue for the comparisons with radiosondes. Meanwhile, Figure 5B also shows the NOAA-19 AMSU-A Ch 8 mission-life standard deviation O-B Ta bias value of about $0.5 \mathrm{~K}$ is an outlier in comparison to the values of about $0.1 \mathrm{~K}$ for the other instrument makes and models at the $55.5 \mathrm{GHz}$ frequency. Mission-life time series of monthly-mean O-B Ta bias values are able to provide some clarity into the stability of the AMSU and ATMS instruments, and these are found in Figure 6 for all relevant channels. 

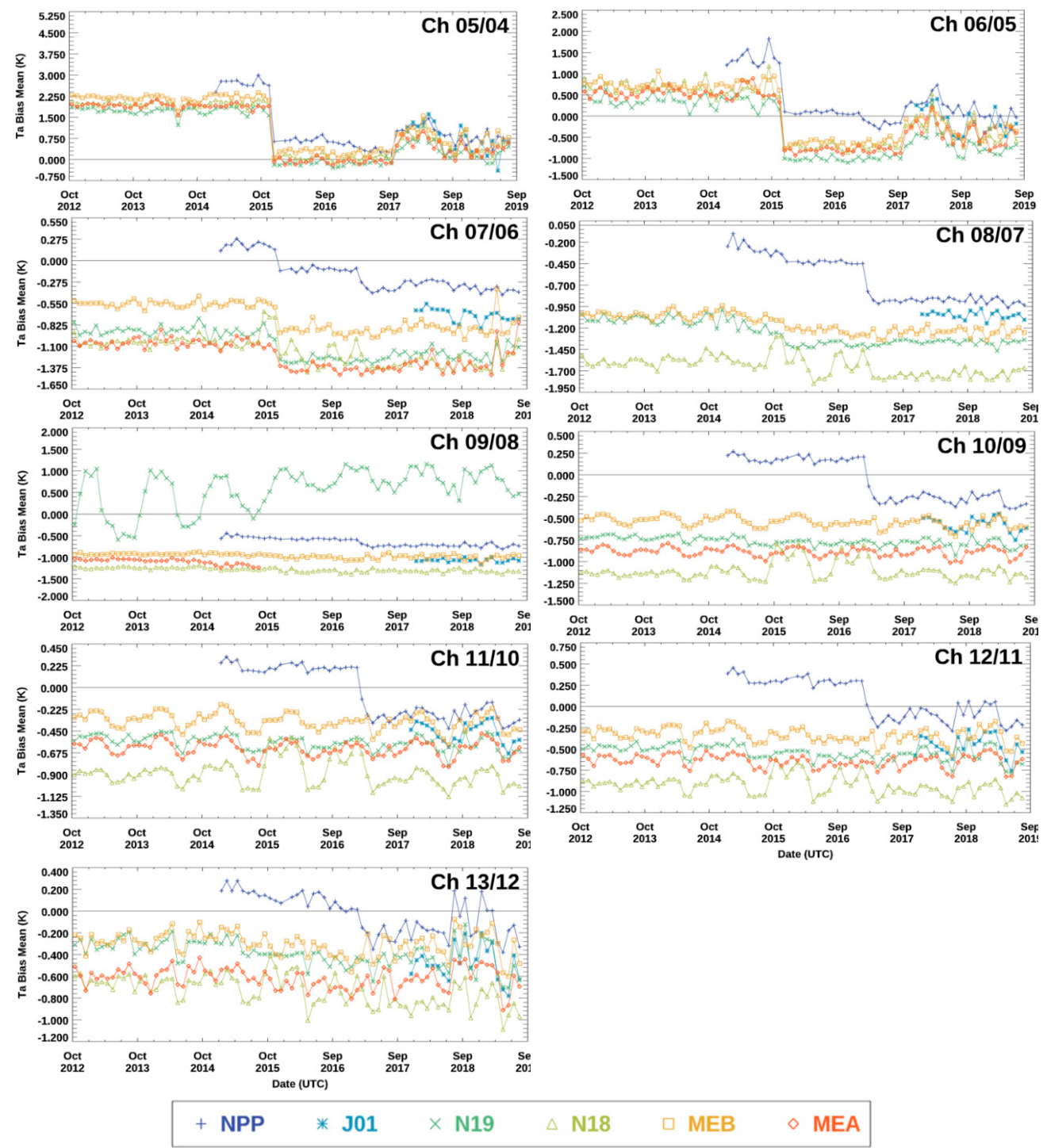

Figure 6. Time series of monthly-mean O-B Ta bias for NOAA-18 (N18), NOAA-19 (N19), Metop-A (MEA), and Metop-B (MEB) AMSU-A, and S-NPP (NPP) and JPSS-1 (J01) ATMS for ATMS/AMSU Ch 5-13/4-12. The legend below the figures denotes the satellite identifier associated with each line plot.

There are many noteworthy features found in these figures. There is a relatively large dip $(-2.0 \mathrm{~K}$ to $-0.5 \mathrm{~K}$ ) in the O-B Ta bias for ATMS/AMSU-A Chs 5-7/4-6 after October 2015, which is due to an update of the GNSS RO "ROAM" [32]. The ROAM is the program name given to the original FORTRAN-77 software that inverts RO signals into physical parameters. These parameters include L1, L2 and ionosphere free bending angles, impact parameter, neutral atmospheric refractivity and "dry" pressure and temperature, height over mean sea-level, latitude and longitude of the estimated ray tangent point (in the Earth fixed reference frame), and azimuth of the occultation plane [33].

Also evident in the figures is a decrease of about -0.5 K for S-NPP ATMS Chs 7-13 in March 2017. According to JPSS Center for Satellite Applications and Research (STAR) Program reports, a Block 2.0 data processing "Build" Transition to Operations (TTO) occurred on 8 March 2017. After this transition, S-NPP ATMS Ta decreases were reported during the post-release software validation activity. These decreases resulted from thermal vacuum testing coefficient updates (version 003) in the ATMS parameter coefficient table. Meanwhile, a rise and fall of O-B Ta bias greater than $0.5 \mathrm{~K}$ in ATMS/AMSU-A Chs 5-6/4-5 between September 2017 and September 2018 is apparent that does not have a clear origin. Finally, the outlier in NOAA-19 Ch 8 can be clearly seen. 
The origins of the NOAA-19 Ch 8 outlier can be visualized with the aid of the STAR Integrated Cal/Val System (ICVS) (https://www.star.nesdis.noaa.gov/icvs/index.php) instrument engineering and housekeeping data plots. Figure 7 represents the NOAA-19 AMSU-A Ch 8 mission-life trend of NEDT distributed by the STAR ICVS. This figure shows significant increases in NOAA-19 AMSU-A Ch 8 NEDT. The following report was logged by the NOAA Office of Satellite and Product Operations on 22 December 2009: "The NOAA-19 AMSU-A Channel 8 NEdT/Gain began experiencing noise on 21 December 2009 (JDAY 355). Only Channel 8 of NOAA-19's AMSU-A seems to be experiencing increased noise levels in the NEdT." Simultaneously, there was a large decrease in instrument gain for this channel, after which it became relatively unstable. These unstable gain variabilities are also reflected in the monthly-mean O-B Ta time series (see Figure 8). In Figure 8, NOAA-19 AMSU-A Ch 8 gain and monthly-mean $\mathrm{O}-\mathrm{B}$ Ta bias variations are shown along with four numbered circles depicting the October 1 date for each year from 2012 to 2015. This shows that phases of the gain and monthly-mean O-B Ta variations are related and simply opposite in sign of each other. This is expected as the measured radiance variation is a function of the inverse gain value.

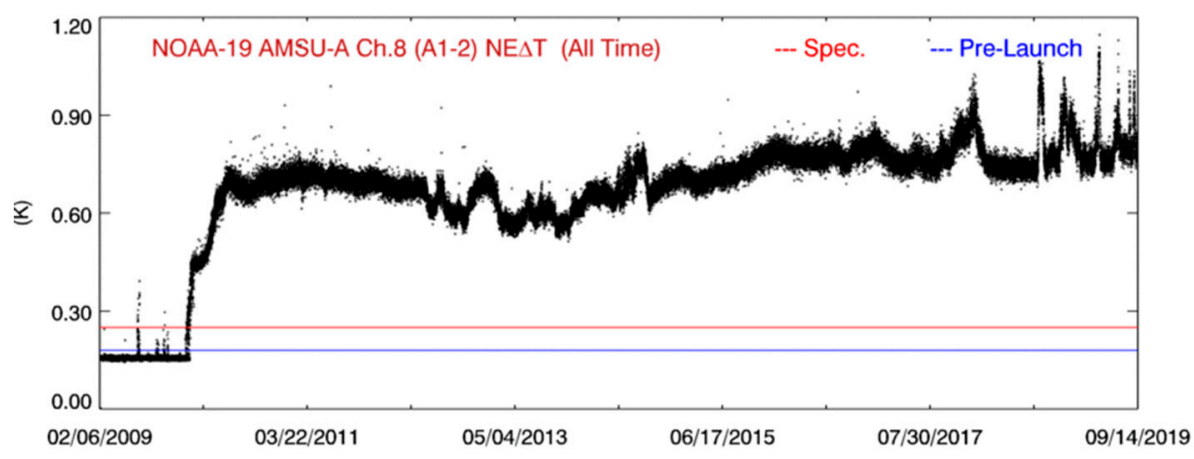

Figure 7. NEDT for NOAA-19 AMSU Channel 8, as shown by the STAR ICVS.

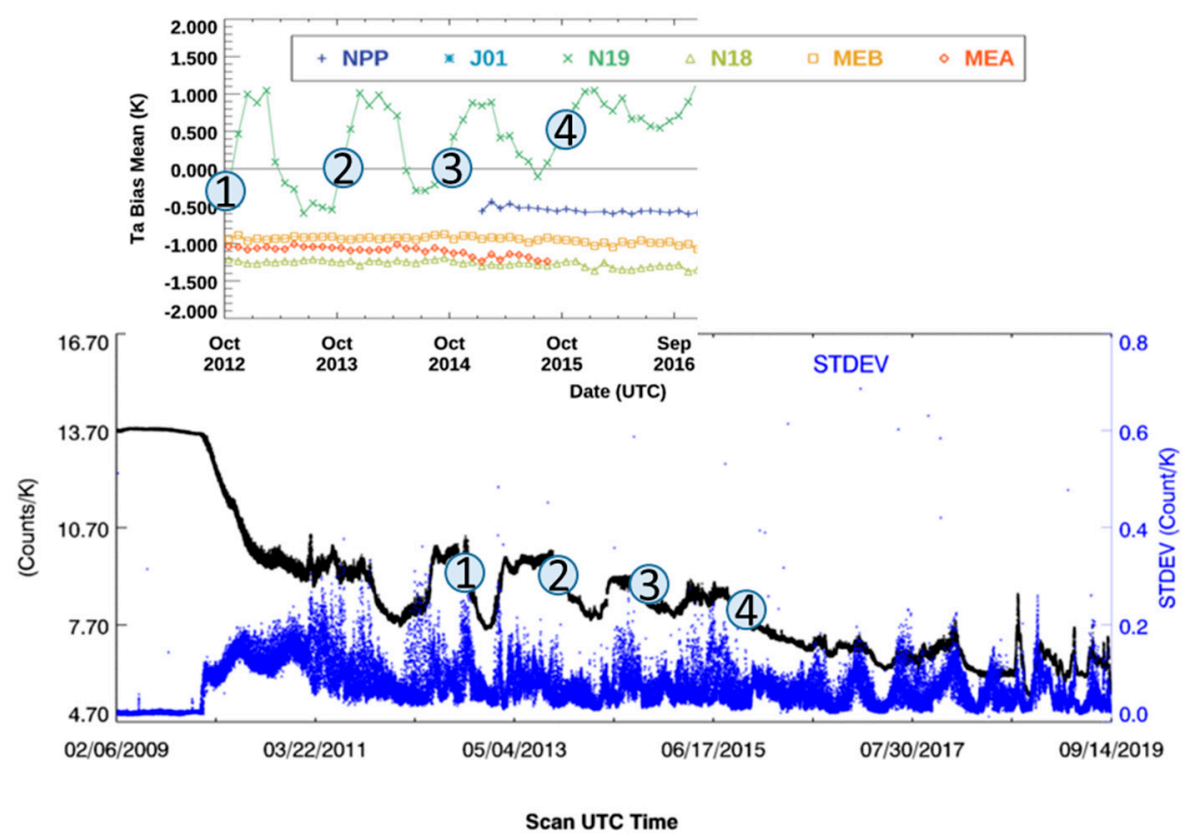

Figure 8. NOAA-19 AMSU Ch 8 Gain (Bottom) and monthly-mean O-B Ta bias (Top). The four circled numbers on these figures represent the October 1 date for years 2012-2015.

The ATMS (AMSU-A) Ch 10-13 (9-12) are found to have subtle but noticeable annual cycles, as shown in Figure 6. The amplitude of these variations is on the scale of $0.1 \mathrm{~K}$ to $0.4 \mathrm{~K}$ for ATMS (AMSU-A) Ch 10 (9) and Ch 13 (12), respectively. This is also reflected in the general tendency for 
the mission-life standard deviation shown in Figure 5B to increase from about $0.05 \mathrm{~K}$ to over $0.1 \mathrm{~K}$ over this channel range. These channels have peak microwave sounder weighting functions between $80 \mathrm{hPa}$ and $20 \mathrm{hPa}$, as shown in Figure 1. Two plausible explanations for these annual cycles are the seasonal $2 \mathrm{~K}$ uncertainty of COSMIC GNSS RO sounding temperatures at levels above $30 \mathrm{~km}$ (about $10 \mathrm{hPa}$ ), as shown by [34], as well as the influence of using the time-independent US Standard Atmosphere temperature and water vapor sounding above $40 \mathrm{~km}$.

\subsection{Monthly and Mission-Life Double-Difference Inter-Sensor Ta Bias Statistical Results}

As mentioned in Section 3.3, the difference between monthly-mean O-B Ta biases of two operational AMSU-A and/or ATMS microwave instruments-i.e., the double difference-computed during their overlap periods provides an indirect estimate of the monthly-mean Ta biases between those instruments. For NOAA-18, NOAA-19, Metop-A and Metop-B AMSU-A and S-NPP and JPSS-1 ATMS microwave instruments, there are six AMSU-A to AMSU-A, eight ATMS to AMSU-A, and one ATMS to ATMS instrument pair(s) possible, where each pair is capable of producing "double-difference" monthly-mean Ta biases. The character of the double-difference Ta biases is revealed in Figure 9. This figure represents the mean of AMSU-A to AMSU-A, ATMS to AMSU-A and ATMS to ATMS monthly minimum and maximum double-difference Ta biases computed over the period of on-orbit operational instrument overlaps. This simplification of presentation is chosen to avoid having 15 plots on one graph.

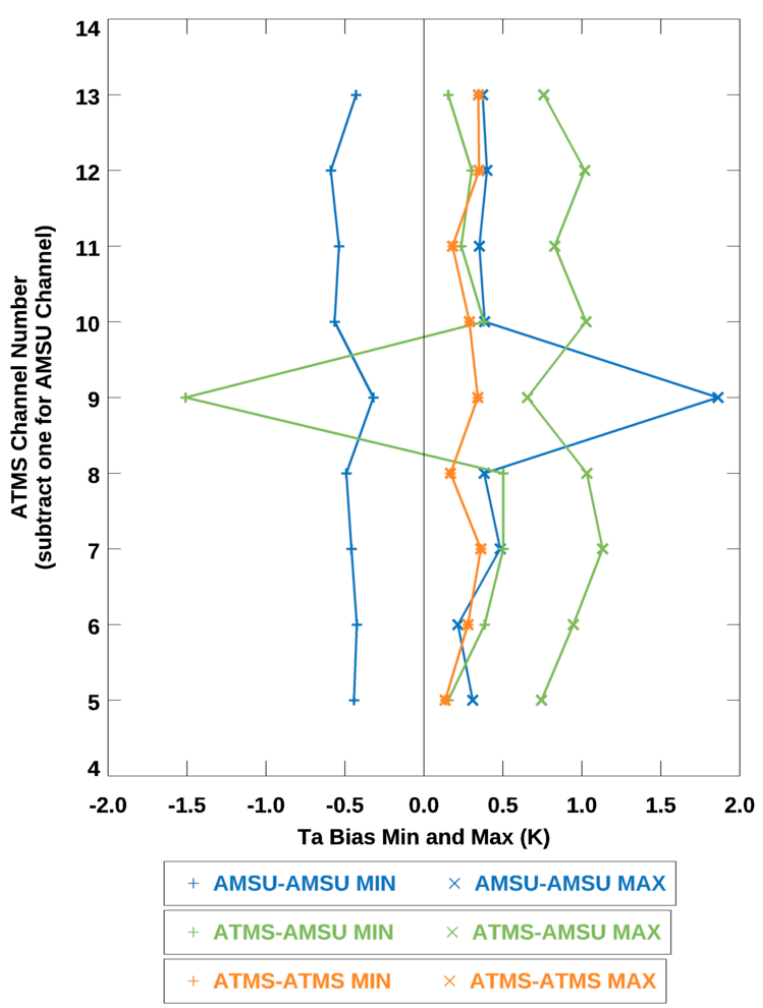

Figure 9. Operational overlap period means of the AMSU-A to AMSU-A, ATMS to AMSU-A, and ATMS to ATMS monthly minimum and maximum double-difference Ta biases. The legends below the figure denote the instrument pair type and statistic associated with each line plot. Note in this figure that the corresponding AMSU-A channel is the ATMS channel number minus one.

Figure 9 shows that the minimum (maximum) double-difference Ta biases between overlapping AMSU-A instrument pairs is on average about $-0.5 \mathrm{~K}(0.5 \mathrm{~K})$, respectively. The exception to this is the double-difference Ta biases associated with NOAA-19 AMSU-A Ch 8. These biases can be as high as $2 \mathrm{~K}$, as a result of the large noise and gain anomalies in this channel discussed in the previous 
section. The results of overlapping ATMS and AMSU-A instrument pair double-difference Ta biases reveal average minimum (maximum) values of approximately $0.25 \mathrm{~K}(0.75 \mathrm{~K})$ when the results from double differences with respect to NOAA-19 AMSU-A Ch 8 are neglected. These results reveal that the AMSU-A to AMSU-A (ATMS to AMSU-A) instrument pairs have measurements that are on average no greater that about $1 \mathrm{~K}(0.5 \mathrm{~K})$ of each other. There is only one overlapping ATMS instrument pair-i.e., between S-NPP and JPSS-1—that has average double-difference Ta biases of approximately $0.3 \mathrm{~K}$. It is important to note that nothing can be said about the absolute accuracies of any of these instruments.

In order to gain a more detailed understanding of these results, in Figure 10 time series of the minimum and maximum monthly-mean Ta bias for the AMSU-A to AMSU-A, ATMS to AMSU-A, and ATMS to ATMS instrument pair(s) are given for all relevant channels.
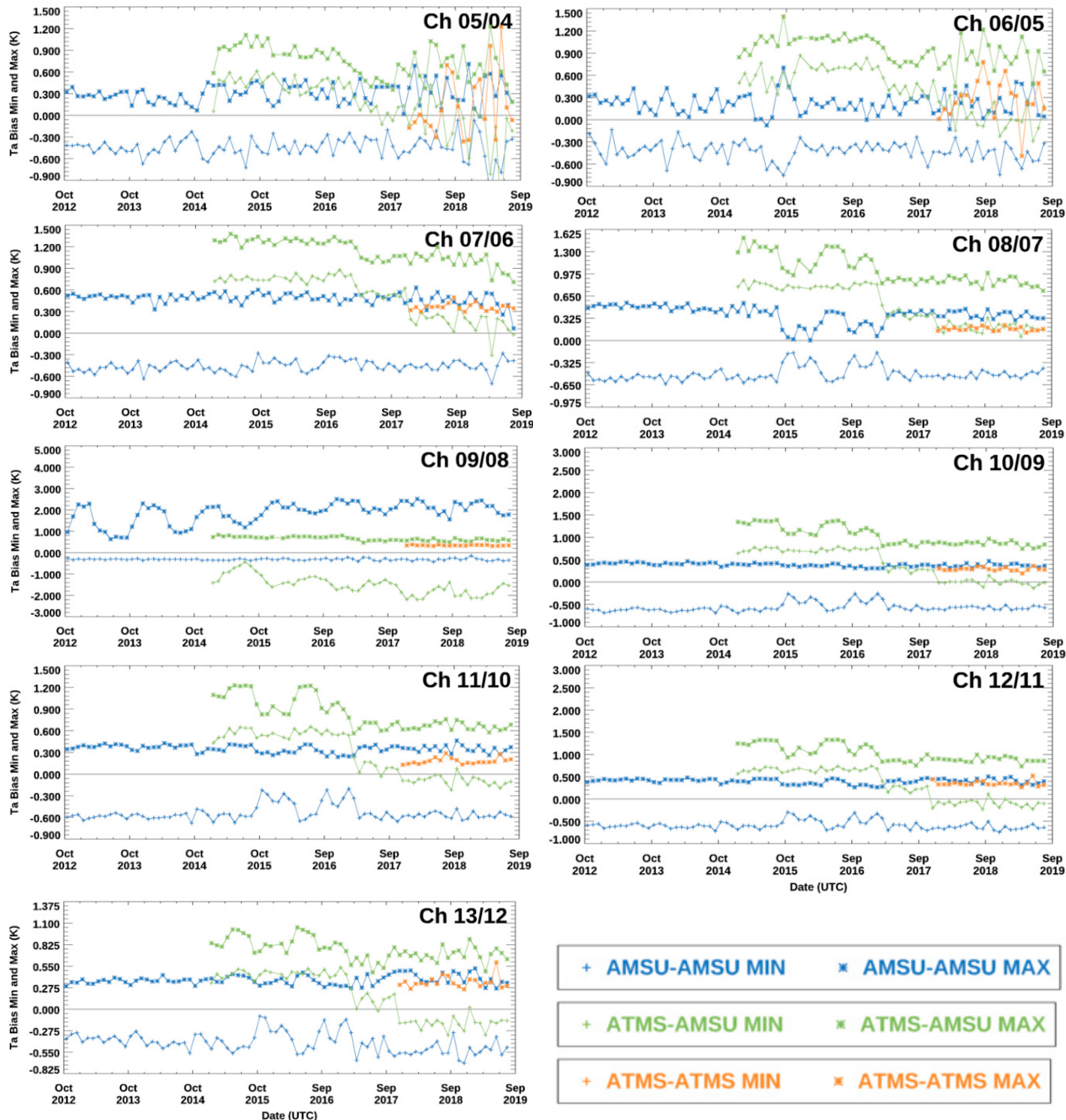

Figure 10. Time series of monthly minimum and maximum AMSU-A to AMSU-A, ATMS to AMSU-A, and ATMS to ATMS double differences Ta biases computed using available monthly-mean O-B Ta biases values for ATMS/AMSU-A Chs 5-13/4-12. The legend in the bottom right corner denotes the pair of instruments and the statistic for a given time series. 
The new information that is accessible in these figures is that the annual cycles that were clearly present in the monthly-mean O-B Ta bias values of Figure 6 for ATMS (AMSU-A) Ch 10-13 (9-12) have largely disappeared in the double-difference Ta time series. A clear exception to this is the elevated values of the AMSU-A to AMSU-A double difference minimum values from June 2015 to June 2017. These are associated with excursions of NOAA-18 AMSU-A O-B Ta bias that are unusually large over this period, which can be seen clearly in Figure 6 for AMSU-A Ch 7 and Chs 9-11.

In the previous section, NOAA-19 AMSU-A Ch 8 monthly-mean O-B Ta bias changes were linked to significant instrument noise and gain changes displayed in the STAR ICVS. Thus, we turn to the STAR ICVS to also investigate a potential NOAA-18 AMSU-A anomaly as well. The NOAA 18 AMSU-A Radio Frequency (RF) Multiplexer (MUX) temperature, and Ch 10 cold space counts, warm space counts, and gain from the STAR ICVS are given in Figure 11A-D, respectively. Note that the RF MUX temperature is considered to be an indicator of the instrument temperature. In Figure 11D, the ATMS Ch 11 and AMSU-A Ch 10 monthly-mean O-B Ta biases are provided to facilitate comparison. During the June 2015 to June 2017 period, these plots show instrument temperature excursions of over $10 \mathrm{~K}$ that are at least 3 times larger than temperature ranges recorded for dates outside this period. These large instrument temperature changes are reflected in $\mathrm{Ch} 10$ cold space and warm target counts, which are used to compute the instrument gain. The resulting changes of instrument gain can be clearly seen to have a similar annual cycle signature compared to the NOAA-18 AMSU-A Ch 10 monthly-mean O-B Tb biases (see Figure 11D).



Figure 11. NOAA-18 AMSU-A RF MUX temperature (A) and Ch 10 cold space (B) and blackbody (C) temperatures. The final plot (D) includes ATMS Ch 11/AMSU-A Ch 10 monthly-mean O-B Ta bias (upper) and NOAA-18 AMSU-A Ch 10 Gain (lower). The dashed purple arrows delineate the June 2015 and June 2017 in each plot. 
An explanation for such large changes in NOAA-18 AMSU-A thermal characteristics during this time may be due to the uncontrolled drift of the NOAA-18 satellite orbit local equator crossing time (LECT). Figure 12 shows that the orbits of all NOAA polar-orbiting satellites before NOAA-20 were allowed to have dramatic LECT changes over their lifetimes. In this figure, it is clear that NOAA-18 has passed through a "terminator" orbit, where its orbital plane has LECT nodes near 0600 and 1800 and is perpendicular to incident solar radiation. The Earth Terminator is defined as the circle that divides its daylight side from its night side. This satellite polar-orbiting configuration could cause solar radiation shining from the side of, or slightly underneath, the satellite to directly heat AMSU-A, or allow it to be shadowed by other instruments, for much of its orbit.

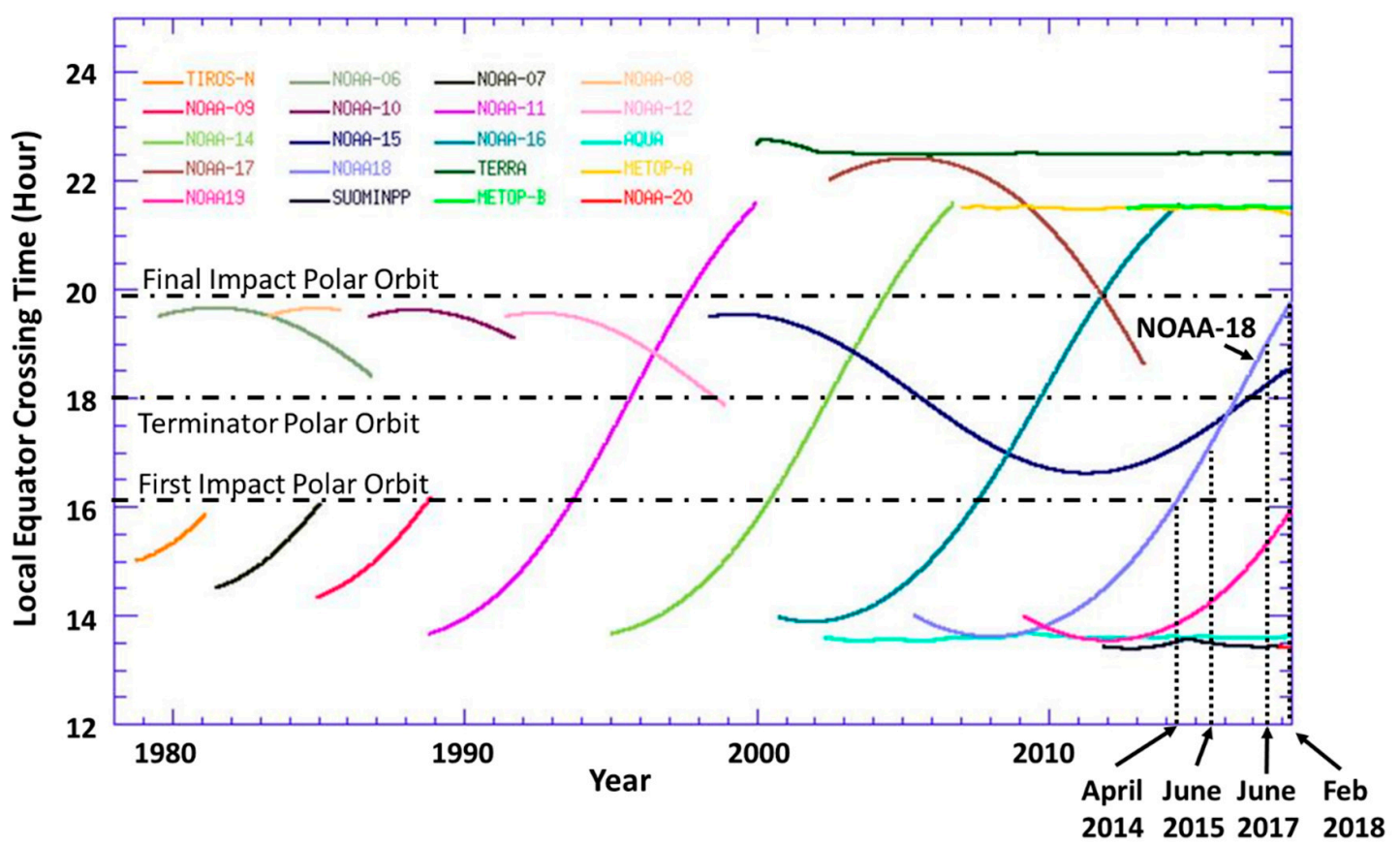

Figure 12. Graph of LECT versus Year for NOAA, Earth Observing System (EOS), and Suomi-NPP polar orbiting satellites. Additionally included is a line representing the 0600/1800 "Terminator Polar Orbit" LECT, and lines representing first and final impact LECT for polar orbiting satellites. The figure is courtesy from the STAR JPSS web site at https://www.star.nesdis.noaa.gov/jpss/images/orbit-drift.jpg.

This affect can be visualized with the aid of the illustration in Figure 13. In this illustration, the location a polar-orbiting satellite crossing the equator where the underside of the satellite is first subject to direct solar illumination is show. At an orbital height of about $848 \mathrm{~km}$, the longitudinal arc angle between the nearest Earth Terminator point and the satellite LECT point is about 28 degrees, which takes about $1 \mathrm{~h}$ and $52 \mathrm{~min}$ to subtend at the earth's rotation rate. Thus, if the tangent point is 0600/1800, then orbital LECT nodes starting at 0408/1608 could begin seeing impacts of solar radiation to instrument thermal characteristics, which would end when satellite LECT drifts to 0752/1952. At this point, instrument thermal behavior would completely go back to normal.

Figures 11 and 12 can be used to roughly test these predictions. According to Figure 12 and these predictions, direct solar radiation should begin affecting the NOAA-18 AMSU-A instrument around April 2014 and end in February 2018. The bottom panel of Figure 11 shows that the AMSU-A instrument gain was clearly anomalous from about August 2014 to April 2018, which is within reasonable agreement for such a back-of-the-envelope theoretical treatment of the phenomenon. The top panel of Figure 11 reflects the large monthly O-B Ta bias anomalies between June 2015 and June 2017 and little or no response to the smaller gain anomalies found the beginning and end of this direct solar radiation period. 


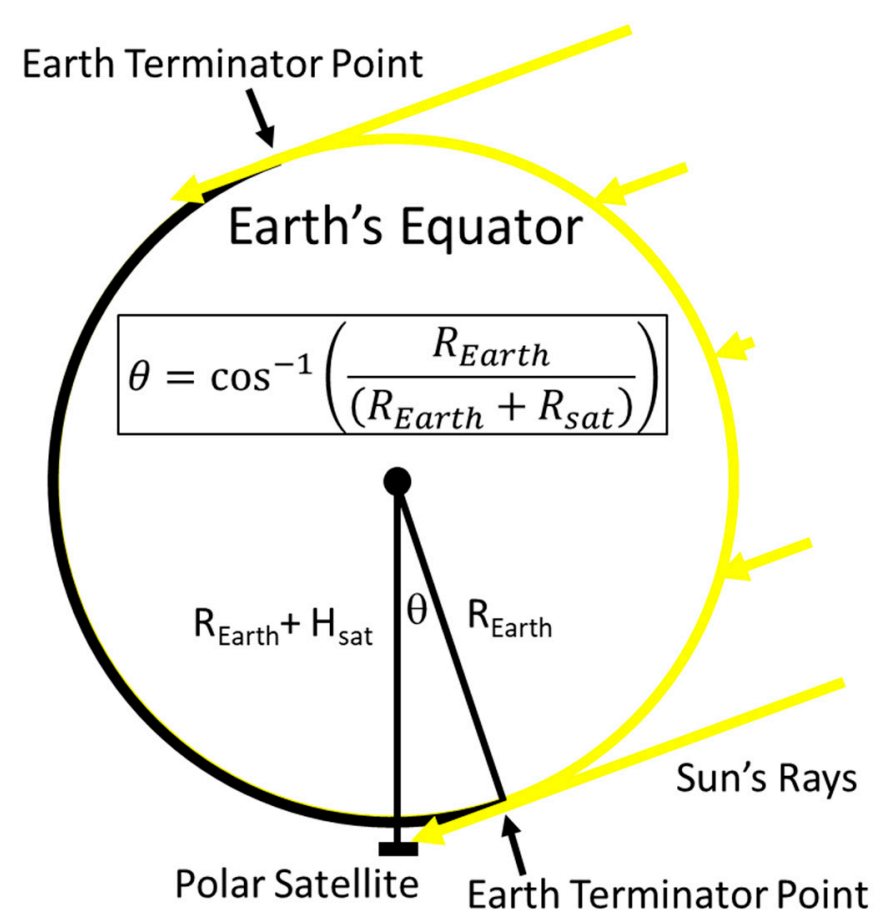

Figure 13. An illustration depicting a polar-orbiting satellite with an altitude $\mathrm{H}_{\text {Sat }}$ above the Earth's equator at an LECT that allows Sun's rays to begin to illuminate the nadir pointing side of the satellite platform. The angle $\theta$ depicts the longitudinal angle between satellite nadir and the Earth Terminator Point where a solar ray striking the satellite meets the earth horizon.

\subsection{Lessons Learned in Using COSMIC RO Soundings to Track and Trend Operational Microwave Sounder Data}

Users of GNSS RO soundings most importantly need to assess their fitness-for-purpose related to the task they want to accomplish. For this study, the purpose of using COSMIC wetPrf soundings is to monitor temporal changes in microwave sounder radiometer O-B Ta biases, and to establish estimates of inter-satellite Ta biases. The microwave sounder radiometer mission-life mean and standard deviation O-B Ta biases clearly show similar character to documented temperature biases between COSMIC wetPrf and radiosonde soundings [31]. Absolute accuracy of O-B Ta biases is not essential to operational microwave sounding radiometer data monitoring, so it is not necessary to account for these COSMIC wetPrf sounding artifacts. On the other hand, radiometric tracking and trending does depend on understanding GNSS RO wetPrf sounding quality stability over space and time. In this case, research by Fan et al. [34] revealed seasonality in COSMIC temperature soundings. Knowledge of this allows us to anticipate and screen out these signals when detecting anomalies in the microwave sounder instrument data. In addition, computing monthly mean O-B Ta bias "double difference" values remove COSMIC wetPrf sounding bias effects when establishing inter-satellite microwave sounder Ta biases. These COSMIC wetPrf sounding effects are considered the same for any two co-orbiting satellites, so they cancel out in the "double difference."

Examples from Sections 4.2 and 4.3 reveal how the O-B Ta bias statistics-computed with support of the CRTM and GNSS RO soundings - can be used to monitor operational microwave radiometer Ta products. Additionally, when these bias statistics are compared to instrument engineering and calibration data, they act together as integral parts of a holistic Integrated Calibration/Validation System that can discern instrument change impacts on these Ta products. This represents a success story related to the use of GNSS RO generated soundings. On the other hand, it was important for the researchers of this study to understand the requirements for, and the strengths and weaknesses of, the GNSS RO generated soundings. 


\section{Conclusions}

The O-B Ta bias parameter computed from operational satellite microwave sounding radiometer Ta observations and collocated forward RTM Tb simulations has been found to be key to monitoring data quality and performing initial instrument anomaly investigations. In this study, COSMIC GNSS $\mathrm{RO}$ atmospheric temperature and moisture (wetPrf) sounding profiles over ocean and equatorward of $60^{\circ}$ latitude are used as input to the CRTM to generate simulated NOAA-18, NOAA-19, Metop-A, and Metop-B AMSU-A and S-NPP and JPSS-1 ATMS Tb values. These simulated Tb values, together with observed Ta values that are nearly simultaneous in space and time, are used to compute O-B Ta bias statistics on monthly time scales for each instrument. In addition, the CRTM-simulated Tb values based on the COSMIC GNSS RO soundings can be used as a transfer standard to inter-compare Ta values from different microwave radiometer makes and models that have the same bands. This is accomplished by computing the "double difference" between monthly-mean Ta bias O-B values from pairs of co-orbiting operational microwave sounding instruments for the corresponding frequency bands.

The collocated radiometer and COSMIC GNSS RO data points available for this research were found to be geographically well distributed and statistically robust, even though the number of samples on a given day dropped from the hundreds to the tens from October 2012 to August 2019. It is discovered that the upper-air sounding channels such as AMSU-A Ch 12 have a great deal more points than surface-influenced channels like AMSU-A Ch 4. This is due to the fact that data associated with GNSS RO sounding levels closest to the surface are more likely to be missing or have the bad data quality flag set.

Mission-life mean O-B Ta bias values plotted as a function of radiometer sounding channel reveal that ATMS Ch 5 (AMSU-A Ch 4) O-B Ta bias values are about $1 \mathrm{~K}$, while they vary between about -1.5 K to $0 \mathrm{~K}$ for ATMS Ch 6-13 (AMSU-A Ch 5-12). This behavior is similar to comparisons of COSMIC wetPrf and radiosonde temperature profiles [31]. There is a prominent NOAA-19 Ch 8 O-B Ta bias outlier of about $0.5 \mathrm{~K}$, which differs substantially from the Ta bias value of about $-1.25 \mathrm{~K}$ for the other instrument makes and models for this $55.5 \mathrm{GHz}$ frequency channel. The mission-life mean O-B Ta bias values cluster within about $0.5 \mathrm{~K}$ of each other for channels with identical frequencies. Meanwhile, the mission-life standard deviation O-B Ta bias values are typically less than $0.2 \mathrm{~K}$, except for NOAA-19 AMSU-A Ch 8 and ATMS Ch 5-6 (AMSU-A Ch 4-5). The ATMS Ch 5-6 (AMSU-A Ch 4-5) have values greater than $0.6 \mathrm{~K}$ for all instruments other than JPSS-1 ATMS, which has a standard deviation value greater than $0.3 \mathrm{~K}$. This upper and lower sounding channel standard deviation disparity is large with respect to COSMIC wetPrf and radiosonde temperature sounding comparisons for levels with pressure less than and greater than $700 \mathrm{hPa}$ [31]. Surface influence of the radiometer channels, which is absent in the radiosonde data, could explain this. Meanwhile, the NOAA-19 AMSU-A Ch 8 mission-life standard deviation O-B Ta bias value of about $0.5 \mathrm{~K}$ is an outlier in comparison to the values of about $0.1 \mathrm{~K}$ for the other instrument makes and models at the $55.5 \mathrm{GHz}$ frequency.

Minimum (maximum) double-difference Ta biases between overlapping AMSU-A instrument pairs is on average about $-0.5 \mathrm{~K}(0.5 \mathrm{~K})$, respectively. The exception to this is the double-difference Ta biases associated with NOAA-19 AMSU-A Ch 8 . These biases can be as high as $2 \mathrm{~K}$ as a result of the large noise and gain anomalies. The results of overlapping ATMS and AMSU-A instrument pair double-difference Ta biases reveal average minimum (maximum) values of approximately $0.25 \mathrm{~K}(0.75 \mathrm{~K})$ when the results from double differences with respect to NOAA-19 AMSU-A Ch 8 are neglected. These results reveal that the AMSU-A to AMSU-A (ATMS to AMSU-A) instrument pairs have measurements that are on average no greater than about $1 \mathrm{~K}(0.5 \mathrm{~K})$ of each other. There is only one overlapping ATMS instrument pair-i.e., between S-NPP and JPSS-1— that has average double-difference Ta biases of approximately $0.3 \mathrm{~K}$. It is important to note that nothing can be said about the absolute accuracies of any of these instruments. One obvious anomaly in the double difference Ta bias values manifested as elevated AMSU-A to AMSU-A minimum values from June 2015 to June 2017. These were shown to be associated with excursions of NOAA-18 AMSU-A O-B Ta bias that are unusually large over this period. 
A significant finding of this study is that efforts to gain insight into mission-life mean and standard deviation O-B Ta bias statistics outliers can be supported with time series of monthly-mean O-B, and "double-difference", Ta bias values, along with relevant instrument engineering and housekeeping data plots from the STAR ICVS. This was exemplified by investigations into the NOAA-18 AMSU-A O-B Ta bias excursions between June 2015 and June 2017 and the long-term ongoing NOAA-19 AMSU-A Ch 8 anomaly. NOAA operational ATMS and AMSU-A data used in numerical weather prediction and climate analysis are essential to protect life and property and maintain safe and efficient commerce. Routine data quality monitoring and anomaly assessment, such as that provided by statistics and time series of individual instrument O-B Ta biases and inter-instrument "double-difference" Ta biases computed with the aid of GNSS RO sounding profiles, is an important tool to sustain data effectiveness. The study also reveals that it is important for users of the GNSS RO sounding profiles to understand the requirements, and strengths and weaknesses, of these data.

In the Introduction, several references are given regarding (1) the Simultaneous Nadir Overpass method to detect inter-satellite Ta biases, as well as (2) the use of NWP output parameters coupled with the CRTM to generate O-B Ta statistics. In future work, research will be performed to compare and contrast results from these legacy methods and the method provided in this paper to highlight their effectiveness for operational microwave sounding instrument data integrity monitoring. In addition, as COSMIC-2 data are now readily available as part of their post-launch check-out, they will be studied for their ability to track and trend microwave sounding instrument data as well.

Author Contributions: Conceptualization, methodology, and software, L.L. and R.I.; formal analysis and investigation, R.I.; resources, Q.L., N.S., and Q.L.; data curation, R.I., N.S., and L.L.; writing一original draft preparation, R.I.; writing—review and editing, R.I., Q.L., and N.S.; supervision, Q.L. and N.S.; project administration and funding acquisition, Q.L. All authors have read and agreed to the published version of the manuscript.

Funding: This research was funded by the Joint Polar Satellite System Program.

Acknowledgments: The author would like to acknowledge all STAR colleagues for their input during the process of writing this manuscript.

Conflicts of Interest: The authors declare no conflicts of interest.

\section{References}

1. English, S.J.; Renshaw, R.J.; Dibben, P.C.; Smith, A.J.; Rayer, P.J.; Poulsen, C.; Saunders, F.W.; Eyre, J.R. A comparison of the impact of TOVS and ATOVS satellite sounding data on the accuracy of numerical weather forecasts. Q. J. Royal Met. Soc. 2000, 126, 2911-2931.

2. McNally, A.P.; Derber, J.C.; Wu, W.-S.; Katz, B.B. The use of TOVS level-1 radiances in the NCEP SSI analysis system. Q. J. Royal Met. Soc. 2000, 129, 689-724. [CrossRef]

3. Zou, C.-Z.; Goldberg, M.D.; Cheng, Z.; Grody, N.C.; Sullivan, J.T.; Cao, C.; Tarpley, D. Recalibration of microwave sounding unit for climate studies using simultaneous nadir overpasses. J. Geophys. Res. 2006, 111, D19114. [CrossRef]

4. Spencer, R.W.; Christy, J.R.; Braswell, W.D.; Norris, W.B. Estimation of tropospheric temperature trends from MSU Channels 2 and 4. J. Atmos. Ocean. Technol. 2006, 23, 417-423. [CrossRef]

5. Mears, C.; Schabel, M.; Wentz, F. A reanalysis of the MSU Channel 2 tropospheric temperature record. J. Clim. 2003, 16, 3650-3664. [CrossRef]

6. Prabhakara, C.; Iacovazzi, R., Jr.; Yoo, J.-M.; Dalu, G. Global warming: Evidence from satellite observations. Geophys. Res. Lett. 2000, 27, 3517-3520. [CrossRef]

7. Cao, C.; Heidinger, A.K. Intercomparison of the longwave infrared channels of MODIS and AVHRR/NOAA-16 using simultaneous nadir observations at orbit intersections. In Earth Observing Systems VII; William, L.B., Ed.; International Society for Optics and Photonics: Bellingham, WA, USA, 2002; Volume 4814, pp. 306-316.

8. Cao, C.; Weinreb, M.; Xu, H. Predicting simultaneous nadir overpasses among polar-orbiting meteorological satellites for the intersatellite calibration of radiometers. J. Atmos. Ocean. Technol. 2004, 21, 537-542. [CrossRef] 
9. Cao, C.; Xu, H.; Sullivan, J.; McMillin, L.; Ciren, P.; Hou, Y. Intersatellite radiance biases for the High Resolution Infrared Radiation Sounders (HIRS) on-board NOAA-15, -16, and -17 from simultaneous nadir observations. J. Atmos. Ocean. Technol. 2005, 22, 381-395. [CrossRef]

10. Iacovazzi, R., Jr.; Cao, C. Quantifying EOS Aqua and NOAA POES AMSU-A brightness temperature biases for weather and climate applications utilizing the SNO method. J. Atmos. Ocean. Technol. 2007, 24, 1895-1909. [CrossRef]

11. Iacovazzi, R., Jr.; Cao, C. Reducing uncertainties of SNO-estimated intersatellite AMSU-A brightness temperature biases for surface-sensitive channels. J. Atmos. Ocean. Technol. 2008, 25, 1048-1054. [CrossRef]

12. Weng, F.; Zou, X.; Wang, X.; Yang, S.; Goldberg, M.D. Introduction to Suomi national polar-orbiting partnership advanced technology microwave sounder for numerical weather prediction and tropical cyclone applications. J. Geophys. Res. 2012, 117, D19112. [CrossRef]

13. Mo, T. Calibration of the Advanced Microwave Sounding Unit-A Radiometers for NOAA-L and NOAA-M; NOAA Technical Report; NESDIS: Silver Spring, MD, USA, 1999; Volume 92, 62p.

14. Goldberg, M.D.; Crosby, D.S.; Zhou, L. The limb adjustment of AMSU-A observations: Methodology and validation. J. Applied Met. 2000, 40, 70-83. [CrossRef]

15. Murphy, R.; Le Vine, D.M.; Barath, F.; Barrett, E.; Bernstein, R.L.; Clark, C.A.; Dozier, J.; Kakar, R.; Njoku, E.; Runge, E.; et al. Earth Observing System Volume IIe: HMRR High-Resolution Multifrequency Microwave Radiometer; NASA: Washington, DC, USA; Goddard Space Flight Center: Greenbelt, Maryland, USA, 1987; Volume 20771, 59p. Available online: https://babel.hathitrust.org/cgi/pt?id=umn.31951d014844120\&view=1up\&seq=4 (accessed on 3 March 2020).

16. Goodrum, G.; Kidwell, K.B.; Winston, W.; Aleman, R. NOAA KLM User's Guide; Indiana University Bloomington Virtual CD ROM/Floppy Disk Library, 1999. Available online: http://webapp1.dlib.indiana. edu/virtual_disk_library/index.cgi/2790181/FID3711/klm/index.htm. (accessed on 7 January 2020).

17. Weng, F.; Zou, X.; Sun, N.; Yang, H.; Tian, M.; Blackwell, W.J.; Wang, X.; Lin, L.; Anderson, K. Calibration of Suomi national polar-orbiting partnership advanced technology microwave sounder. J. Geophys. Res. Atmos. 2013, 118, 11-187. [CrossRef]

18. Han, Y.; Weng, F.; Zou, X.; Yang, H.; Scott, D. Characterization of geolocation accuracy of Suomi NPP Advanced Technology Microwave Sounder measurements. J. Geophys. Res. Atmos. 2016, 121, 4933-4950. [CrossRef]

19. Zou, X.; Vandenberghe, F.; Wang, B.; Gorbunov, M.E.; Kuo, Y.-H.; Sokolovskiy, S.; Chang, J.C.; Sela, J.G.; Anthes, R.A. A ray-tracing operator and its adjoint for the use of GPS/MET refraction angle measurements. J. Geophys. Res. 1999, 104, 22301-22318. [CrossRef]

20. Healy, S.; Eyre, J. Retrieving temperature, water vapor and surface pressure information from refractivity-index profiles derived by radio occultation: A simulation study. Q. J. Royal Meteorol. Soc. 2000, 126, 1661-1683. [CrossRef]

21. Palmer, P.I.; Barnett, J.; Eyre, J.; Healy, S. A non-linear optimal estimation inverse method for radio occultation measurements of temperature, humidity, and surface pressure. J. Geophys. Res. 2000, 105, 17513-17526. [CrossRef]

22. Kishore, P.; Namboothiri, S.P.; Jiang, J.H.; Sivakumar, V.; Igarashi, K. Global temperature estimates in the troposphere and stratosphere: A validation study of COSMIC/FORMOSAT-3 measurements. Atmos. Chem. Phys. Discuss. 2008, 8, 8327-8355. [CrossRef]

23. Yu, X.; Xie, F.; Ao, C.O. Evaluating the lower-tropospheric COSMIC GPS radio occultation sounding quality over the Arctic. Atmos. Meas. Tech. 2018, 11, 2051-2066. [CrossRef]

24. Anthes, R.A.; Bernhardt, P.A.; Chen, Y.; Cucurull, L.; Dymond, K.F.; Ector, D.; Healy, S.B.; Ho, S.-P.; Hunt, D.C.; Kuo, Y.-H.; et al. The COSMIC/FORMOSAT-3 mission: Early results. Bull. Am. Meteorol. Soc. 2008, 89, 313-333. [CrossRef]

25. Weng, F.; Zhao, L.; Ferraro, R.; Poe, G.; Li, X.; Grody, N. Advanced microwave sounding unit cloud and precipitation algorithms. Radio Sci. 2003, 38, 8086-8096. [CrossRef]

26. Zou, X.; Lin, L.; Weng, F. Absolute calibration of ATMS upper level temperature sounding channels using GPS RO observations. IEEE Trans. Geosci. Remote Sens. 2014, 52, 1397-1406. [CrossRef]

27. Han, Y.; van Delst, P.; Liu, Q.; Weng, F.; Yan, B.; Treadon, R.; Derber, J. JCSDA Community Radiative Transfer Model (CRTM)_Version 1; NOAA Technical Report; NESDIS: Silver Spring, MD, USA, 2006; Volume 122, 40p.

28. Weng, F. Advances in radiative transfer modeling in support of satellite data assimilation. J. Atmos. Sci. 2007, 64, 3803-3811. [CrossRef] 
29. Han, Y.; van Delst, P.; Weng, F.; Liu, Q.; Groff, D.; Yan, B.; Chen, Y.; Vogel, R. 2010: Current status of the JCSDA community radiative transfer model (CRTM). In Proceedings of the 17th International ATOVS Study Conference, Monterey, CA, USA, 14-20 April 2010; World Meteorological Organization: Geneva, Switzerland, 2010.

30. Shouguo, D.; Yang, P.; Weng, F.; Liu, Q.; Han, Y.; van Delst, P.; Li, J.; Baum, B. Validation of the community radiative transfer model. J. Quant. Spectrosc. Radiat. Transf. 2011, 112, 1050-1064.

31. Wang, B.-R.; Liu, X.-Y.; Wang, J.-K. Assessment of COSMIC radio occultation retrieval product using global radiosonde data. Atmos. Meas. Tech. 2013, 6, 1073-1083. [CrossRef]

32. Sokolovskiy, S.; CDAAC Team. Improvements, Modifications, and Alternate Approaches in the Processing of GPS RO Data. ECMWF/EUMETSAT Radio Occultation Meteorology (ROM) Satellite Applications Facility (SAF): Reading, UK. Available online: https://cdaac-www.cosmic.ucar.edu/cdaac/doc/documents/ Sokolovskiy_newroam.pdf (accessed on 8 January 2020).

33. Sokolovskiy, S. Algorithms for Inverting Radio Occultation Signals in the Neutral Atmosphere. COSMIC Data Analysis and Archive Center (CDAAC). Available online: https://cdaac-www.cosmic.ucar.edu/cdaac/ doc/documents/roam05.doc (accessed on 8 January 2020).

34. Fan, Z.Q.; Sheng, Z.; Shi, H.Q.; Yi, X.; Jiang, Y.; Zhu, E.Z. Comparative assessment of COSMIC Radio occultation data and TIMED/SABER satellite data over china. J. Appl. Meteorol. Clim. 2015, 54, 1931-1943. [CrossRef]

(C) 2020 by the authors. Licensee MDPI, Basel, Switzerland. This article is an open access article distributed under the terms and conditions of the Creative Commons Attribution (CC BY) license (http://creativecommons.org/licenses/by/4.0/). 